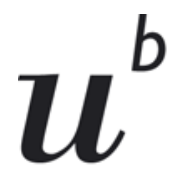

b

UNIVERSITÄT

BER N

Faculty of Business, Economics and Social Sciences

Department of Economics

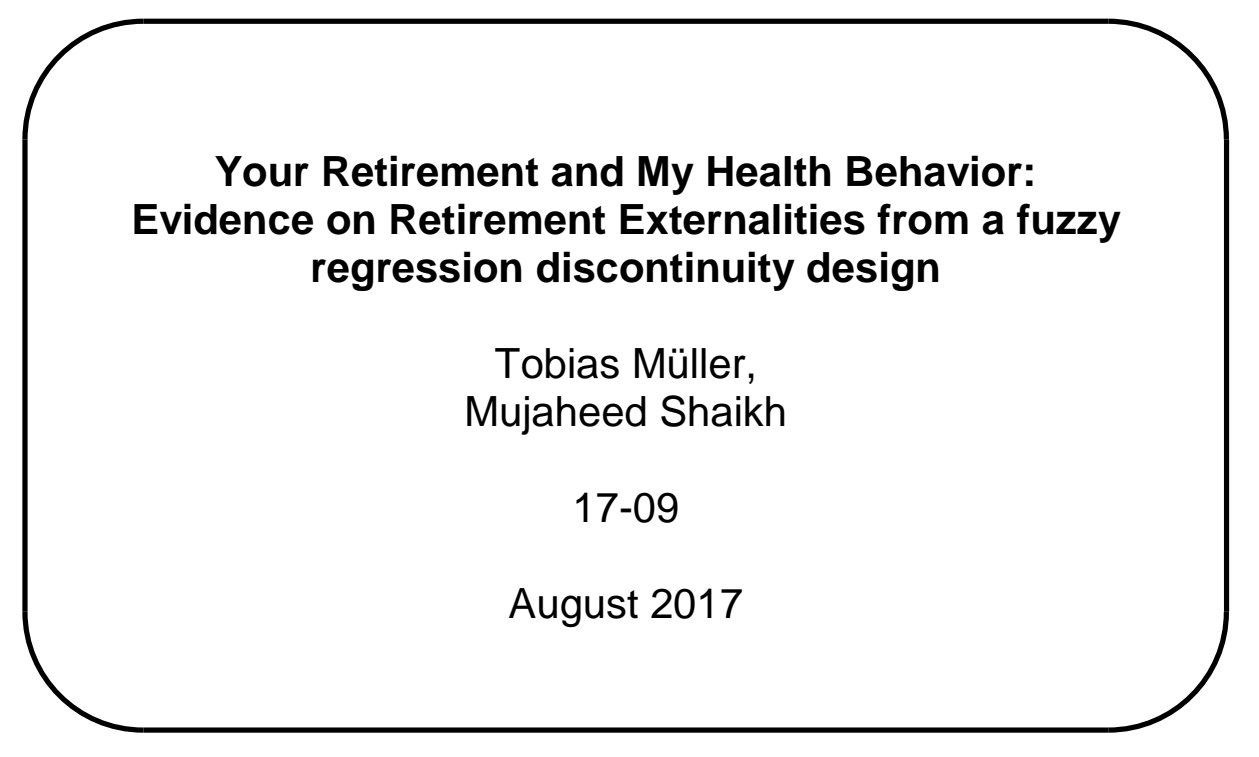

DISCUSSION PAPERS 


\title{
Your Retirement and My Health Behavior: Evidence on Retirement Externalities from a fuzzy regression discontinuity design*
}

\author{
Tobias Müller ${ }^{\dagger 1}$ and Mujaheed Shaikh ${ }^{\ddagger 2}$ \\ ${ }^{1}$ University of Bern \\ ${ }^{2}$ Vienna University of Economics \& Business
}

15 August, 2017

\begin{abstract}
This paper presents evidence on intra-household retirement externalities by assessing the causal effect of spousal retirement on various health behaviors and health status across 19 European countries. We identify partner's and own retirement effects by applying a fuzzy regression discontinuity design using retirement eligibility as exogenous instruments for spousal and own retirement status. We find significant increases in the frequency and intensity of alcohol consumption combined with a significant decrease in moderate physical activities as a response to partner's retirement. In line with the existing literature, we find that own retirement has significant positive effects on engaging in moderate and vigorous physical activities but also leads to a significant increase in the frequency of alcohol intake. Overall, subjective health is negatively affected by spousal retirement and positively by own retirement.
\end{abstract}

JEL Classification: J26; I12; C26

Keywords: Retirement Externalities, Health behavior, Fuzzy Regression Discontinuity Design

\footnotetext{
* Acknowledgments: We are grateful to Stefan Boes, Markus Reisinger, Marisa Miraldo, Michael Gerfin, Matteo Galizzi, Simone Ghislandi, Renata Kosova, Kaspar Wüthrich, Sonja Kassenboehmer, Ines Berniell, and Eugenio Zuchelli for helpful comments at an early stage of this paper. We also thank participants at the Royal Economic Society Junior Researcher Symposium, Health Economists' Study Group meeting, Australian Health Economics Society doctoral workshop, and the Center for Health, Policy and Economics seminar (University of Lucerne), Frankfurt School of Finance and Management doctoral workshop. This paper won the best paper prize at the Portuguese health economics association conference and it was concieved and largely written when MS was a doctoral student at the Frankfurt School of Finance \& Management.
}

${ }^{\dagger}$ First author. Schanzeneckstrasse 1, 3001 Bern, Switzerland, email: tobias.mueller@vwi.unibe.ch

${ }^{\ddagger}$ Corresponding author. Welthandelsplatz 1, 1020 Vienna, Austria, email: mujaheed. shaikh@wu.ac.at 


\section{Introduction}

Retirement related reforms and legislation have been subjected to great debate particularly in the developed world where a rapidly ageing population is posing considerable challenges to the affordability of pension systems. Simultaneous increases in life expectancy have increased costs for the treasuries. For example, the average amount of time spent in retirement across OECD countries has increased from 11 years in 1970 to 18 years in 2012 for men, and from 15 years to 22.5 years for women in the same period (OECD, 2014). Concurrently, public expenditures on pensions also increased in most OECD countries over the past years, with some countries even doubling them relative to national income (OECD, 2014). As a result, many countries have been contemplating changes in official retirement ages and are aiming to raise them in order to secure the viability of statutory social security funds.

There is a growing consensus that retirement reforms, especially changes in retirement age, should carefully account for adverse social and economic effects arising due to individuals retiring either earlier or later, and any actions that alter current policies must discuss both long-term and short-term effects. While the usual focus of economists is largely on the effects of retirement on income and consumption behavior (Charles, 2002; Battistin, 2009), much of the recent literature has now started to focus on other broader outcomes such as leisure activities (Stancanelli \& Soest, 2016), home production (Stancanelli \& Soest, 2012), cognitive abilities (Mazzonna \& Peracchi, 2012) and health and health behavior (Coe \& Lindeboom, 2008; Neuman, 2008; Johnston \& Lee, 2009; Coe \& Zamarro, 2011; Behncke, 2012; Insler, 2014; Eibich, 2015). Such broader outcomes are now gaining a foothold in the political debates on retirement legislations and it is a growing view that if effective retirement policies are to be framed, different aspects of life that retirement affects must be considered. However, one aspect that has largely been ignored within this strand of literature is the assessment of externalities arising due to retirement.

It is surprising that such externalities have not received much attention in the literature since there are several reasons why we believe these would exist. It is unanimously agreed that retirement is an important life changing event which can be particularly stressful to the retirees and those around them through spillover effects (Wheaton, 1990; Coe \& Zamarro, 2011). Even though a single entity retires, it is clear that retirement sets in motion a sequence of events that have interaction effects with others in the household and thus may affect the behavior of others (Wheaton, 1990). Further, the propensity of an individual to behave in a certain way may vary with the characteristics and the behavior of other individuals around (Manski, 1993). Indeed there is overwhelming evidence on such endogenous and exogenous social effects; where endogenous effects refer to the behavior of an individual varying with the behavior of others, and exogenous effects refer to the behavior of an individual varying with the characteristics of others (see Manski, 1993; Banerjee, 1992; Bhickchandani et al., 1992; Duflo \& Saez, 2002, 2003). There is a growing body of both theoretical and empirical literature that identifies such effects in education, savings and retirement decisions, technology adoption etc. (Banerjee \& Besley, 1991; Bhickchandani et al., 1992; Duflo \& Saez, 2002, 2003; Vergari, 2004). While the literature on this topic largely discusses group behavior and group characteristics either in terms of groups of individuals or groups of firms, we attempt to draw on this literature and apply it to the behavior of individuals within a household. Following a similar line of reasoning, it seems plausible to 
presume that the behavior or characteristics of individuals directly affect the behavior of others within the household imposing externalities on others (either positive or negative). While in the case of groups these are often termed herd externalities (Banerjee, 1992), in the household case we may call them intra-household externalities ${ }^{1}$.

The identification of such retirement related intra-household externalities, specifically in terms of health behaviors, and their implications on health is the main contribution of this paper. We identify the causal effect of being retired (a characteristic of an individual) on the health behaviors of the other individual (partner) in the household. To this end we use a fuzzy regression discontinuity (RD) design which accounts for the endogeneity of the retirement decision by exploiting the legislation on retirement eligibility, which makes the probability of being in retirement a discontinuous function of age. We use data from four waves of the Survey of Health, Ageing and Retirement in Europe (SHARE) for 19 European countries .

First, we find that the probability to retire shows a significant discontinuity at the country specific retirement age thus supporting our identification strategy at the outset. Second, our $\mathrm{RD}$ estimates show that spousal retirement has a positive and significant effect on the frequency of alcohol intake, the number of drinks consumed per day, binge drinking and finally on the likelihood of having a drinking problem. Also, our analysis provides evidence for a significant decrease in moderate physical activity but no effect on vigorous physical activity. In contrast, we find that own retirement has a significant and positive effect on engaging in activities which require moderate or vigorous levels of energy. At the same time, own retirement also leads to an increase in the frequency of alcohol intake, but not the amount consumed.

On exploring heterogeneity in the results by own retirement status, we do not find a statistically significant difference in any of the health behaviors between individuals with and without an already retired partner. However, our estimates indicate a significant increase in cigarettes smoked per day among those with a smoking partner. Overall, we find that partner's retirement affects subjective health negatively and own retirement shows a positive effect on subjective health. The results are robust to a battery of sensitivity tests and different window widths. In addition, the standard RD validity checks provide no evidence for violations of local random assignment reinforcing our identification strategy.

The remainder of the paper is organized as follows: In section 2 we discuss relevant related literature. Section 3 describes the data and variables used in the analysis. In section 4, we present our identification strategy and RD validity checks. Section 5 presents our main results and sheds light on effect heterogeneity. Section 6 turns the focus to robustness checks, placebo tests and possible anticipation effects. We draw final conclusions and discuss policy implications in section 7 .

\section{Relevant Literature}

This paper contributes to the literature that assesses the different determinants of specific risky health behaviors such as smoking, alcohol consumption, and physical activity. Several factors such as income, education, advertising and time preferences have been analyzed in the past

\footnotetext{
${ }^{1}$ Previous studies have identified such externalities in different contexts such as health and literacy related intra-household externalities; see Miller \& Mobarak, 2013; Lindelow, 2008; Gibson, 2001.
} 
as important determinants of such health behaviors (for a comprehensive review see Cawley \& Ruhm, 2011). We extend this literature by analyzing the impact of spousal retirement on health status and risky behaviors such as alcohol intake, smoking and reduced physical activity. While the main focus of the paper is on partner's retirement effects, these may not be independent of own retirement effects especially if couples make joint retirement decisions, time their retirement together or retire due to partner's ill-health ${ }^{2}$. In order to ensure that the effects we find of partner's retirement are not in anyway driven by own retirement, we include own retirement in all our specifications. Therefore, we also contribute to the literature that assesses the effects of own retirement on own health behaviors. Further, the paper also makes a contribution to the literature in labour economics where analyzing the effects of changes in social security legislations have long been a matter of great interest. While changes in such legislations involve changing different aspects, retirement age changes are common and heavily debated (OECD, 2013).

We discuss the relevant literature by dividing it into two broad strands: the first strand looks at prior evidence of the effects of own retirement on own health and health behaviors. The second strand focuses on the effects of partner's retirement on own health and health behaviors.

With respect to the first strand of literature, despite the abundant evidence on own retirement effects on health (e.g. Dave et al., 2008; Van Solinge, 2007; Bamia et al., 2008; Coe \& Lindeboom, 2008; Neumann, 2008; Johnston \& Lee, 2009; Coe \& Zamarro, 2011; Behncke, 2012; Bonsang et al., 2012; Blake \& Garrouste, 2013; Bloemen et al., 2013; Celidoni et al., 2013; Insler, 2014; Eibich, 2015; Gorry et al., 2015; Fitpatrick \& Moore, 2016) and health behaviors (e.g. Formann-Hoffman et al., 2008; Chung et al., 2009; Insler, 2014; Eibich, 2015), the literature remains inconclusive. For example, while Dave et al., (2008) find that retirement leads to a decrease in physical and mental health in the U.S. Health and Retirement Study, Coe \& Zamarro (2011) find a health preserving effect of retirement using European data. More recent studies such as Eibich (2015) find that retirement improves subjective health in a sample of the German population - others such as Fitpatrick \& Moore (2016) use administrative data from the U.S. and find an increase in mortality post-retirement. While earlier studies ranged from being descriptive in nature (Bamia et al., 2007) to exploiting panel dimensions (Dave et al., 2008), more recent evidence relies upon nuanced techniques such as using social security eligibility to address endogeneity issues (Eibich, 2015; Gorry et al., 2015; Fitzpatrick \& Moore, 2016). We follow a similar strategy in our paper.

With respect to the second strand of literature, prior evidence is largely centered around the effects of partner's retirement on more general outcomes such as marital relationships, household consumption, home production and joint leisure (Szinovacz, 1980; Stancanelli \& Soest, 2012; 2014; Hospido \& Zamarro, 2014; Banks et al., 2010; Coile, 2004; Hallberg, 2003). Perhaps more relevant for our paper is the limited evidence of partner's retirement on own health. Szinovacz \& Davey (2004) assess if spousal employment and length of retirement affect an individual's postretirement depressive symptoms. Drawing pooled data from the Health and Retirement Survey and using, primarily, ordinary least squares (OLS) regressions, they find that recently retired men are negatively affected by partner's employment. Joint retirement has a beneficial effect on men in general, but the positive effects of female partner's retirement depend on enjoyment of joint activities. More recently, Bertoni \& Brunello (2017) assess the causal effect

\footnotetext{
${ }^{2}$ We address such issues in our robustness tests section 6 .
} 
of husband's retirement on wife's mental health using Japanese data. Specifically, they look at mental health outcomes such as stress, depression and inability to sleep and find a positive effect of husband's retirement. Eibich (2015) assessed heterogeneity in own retirement effects by partner's retirement status and finds no heterogeneity in the results with respect to partner's retirement status.

The mixed evidence with regards to the effect of own retirement and the scant literature on the topic of retirement related externalities with respect to health behaviors thus leaves substantial scope for further research. In this paper we contribute by addressing this gap in the literature.

\section{Data}

Much of the evidence on the effects of retirement stems from the US, in particular from the Health and Retirement Study (HRS) due to the longitudinal and detailed nature of the survey. For Europe, the Survey of Health, Ageing and Retirement in Europe (SHARE) (Börsch-Supan, 2016a; 2016b; 2016c; 2016d), modeled largely around the HRS, provides an excellent opportunity to study retirement effects. The health effects of retirement have been studied using the SHARE survey (see for example Coe \& Zamarro, 2010; Mazzona \& Peracchi, 2012; Celidoni et al., 2013; Godard, 2015); however, ample scope exists to study health behaviors and specifically externality effects which have not been analyzed to date with this data.

SHARE is a multi-disciplinary panel survey conducted across European countries and includes rich micro data related to socio-economic status, health and employment, and social and family networks amongst several others. The first wave began in 2004 and since then computer assisted personal interviews are conducted every two years with individuals aged 50 and over in the participating countries. More than 120,000 respondents have participated and over 297,000 interviews have been conducted so far. We use four waves of SHARE (2004, 2006/07, 2011/12, and 2013) and include 19 European countries in our analysis ${ }^{3}$. SHARE is a representative survey of individuals in a country and a balanced representation of various regions within Europe.

\subsection{Sample Construction}

The focus of this paper is the identification of retirement effects. It is therefore important to understand what 'retirement' means in the SHARE survey. Retirement is based on a self-reported indicator where the respondents are asked about their current job situation and can select either retired, employed/self-employed, unemployed, permanently sick or disabled, homemaker or other. If necessary, retirement is explained to the respondents as retired from own work, including semi-retired, partially retired or early retired.

\footnotetext{
${ }^{3}$ Note that we do not include wave 3 of SHARE, i.e., SHARELIFE which focuses on people's life histories. The countries included in the analysis are Austria, Belgium, Czech Republic, Denmark, France, Germany, Greece, Ireland, Italy, Netherlands, Poland, Spain, Sweden, Switzerland, Luxembourg, Hungary, Portugal, Slovenia and Estonia. Poland was part of waves 2 and 4, Ireland took part only in wave 2; Czech Republic took part in waves 2, 4 and 5. Estonia, Hungary, Portugal and Slovenia entered SHARE in wave 4 and only Estonia and Slovenia were part of wave 5. Luxembourg entered SHARE only in wave 5.
} 
Consequently, our retirement indicator is one for those individuals who selected 'retired' as their current job situation and zero otherwise (see section 3.3 for more details). Note however that we demonstrate in the robustness section 6.1 that our findings are robust against the exclusion of individuals who reported going into retirement due to ill-health or individuals that retired together with their partner on purpose. Furthermore, we only consider individuals within a window of \pm 3 years around the official retirement age. This restriction allows us to identify partner's and own retirement effects with enough precision, while at the same time considering only those individuals with proximity to the retirement eligibility threshold ${ }^{4}$. Since our primary aim is to assess the impact of partner's retirement, it is important that both partners took part in the survey so that we have information about partner's employment status, health behaviors and other variables that we require. We therefore include only those observations for which data on both partners was available. Applying these sample restrictions leaves us with an unbalanced panel of around 23'598 observations with some missing values on one or more of the dependent variables.

Our estimation sample includes 57\% retired individuals. Among the retirees, around $66 \%$ have retired partners while among the non-retirees around $51 \%$ have partners that are retired. The survey also asks respondents the reason for retirement to which almost $82 \%$ of our sample reports either eligibility for public or private pensions, or being offered an early retirement option. We expect a substantial proportion of our estimation sample to be eligible for old-age benefits and out of the labour force since these usually become payable between ages 60 and 65 along with a common requirement of withdrawal from the labour force. We check this and find that $89 \%$ of our sample reports receiving old-age pension benefits. Individuals are also asked if they have done any paid work during the last four weeks/last interview, either as an employee or self-employed even if only for a few hours. $89 \%$ of our estimation sample reports that they have not done any paid work, indicating that these are out of the labour force.

In any $\mathrm{RD}$ design it is imperative that we focus on individuals that are as close as possible to the cutoff point (i.e. the official retirement age). However, individuals that are excluded from our sample (i.e. those having retired partners beyond the 3 year window) may not only affect our sample composition and its characteristics in different ways, but may also show differential health and health behavior effects. For example, within the excluded sample if male partners are older than female partners then this may leave us with a relatively healthier sample of women if the retired partner is a male; similarly a relatively less healthy sample of men if the retiring partner is female.

As expected, retired women are as much as 2 years younger than retired men on average. This age difference is statistically significant at a $1 \%$ level. We then assess if there are significant differences in other characteristics of this sample compared to our actual estimation sample. Of particular concern would be the difference in predetermined characteristics such as education, marital status, and divorce rates between the estimation sample and the excluded sample. However, we do not find any statistically significant differences in those characteristics between the two samples. Furthermore, we also do not find a statistically significant difference in average income. Consequently, we analyze if the outcome variables are significantly different

\footnotetext{
${ }^{4}$ We also perform sensitivity tests using different window widths, the results of which are presented in section 6.1.
} 
between them and we do find significant differences: the estimation sample is healthier on average, is more physically active, smokes less cigarettes, and consumes more alcohol. For a detailed overview of the variables in the data set see the summary statistics in table 1 .

— Insert table 1 about here -

\subsection{Outcome Variables}

\subsubsection{Health behaviors}

While several behavioral risk factors may be related to chronic health conditions and subsequent health care costs, the most important among them are smoking, drinking and obesity (Sturm, 2002). Indeed, many diseases share these common risk factors (Scarborough et al., 2011). SHARE provides a rich set of variables related to physical activity, alcohol consumption and smoking behavior. We explain the choice of each behavioral indicator in what follows and assess the response of each of these indicators to partner's and own retirement in section 5.

\section{Physical Activity}

The first health behavior we focus on is physical activity. Promotion of physical activity is widely acknowledged as a cost effective means of reducing the economic burden on health systems arising due to chronic degenerative conditions (Roux et al., 2008). A significant proportion of health care costs have been attributed to physical inactivity; for example, Katzmartzyk et al. (2000) report direct costs of physical inactivity to be around USD 2.1 billion. Similarly, Kolditz (1999) reports costs of upto USD 24 billion for the United States due to physical inactivity. It is therefore worthwhile to assess the effects of retirement on physical activity. In our analysis we consider two types of physical activity indicators; one capturing moderate physical activity and the other vigorous physical activity. In SHARE respondents report on how often they engage in moderate or vigorous physical activity. The moderate physical activity indicator reports on activities that require a moderate level of energy such as gardening, cleaning the car or going on a walk. The vigorous physical activity measure on the other hand reports on activities that require a high level of energy such as sports, heavy housework, or a job that involves physical labor. For our analysis, we generate two binary indicators that take a value of one if the respondent reports "More than once a week" and zero if they report once a week or less. As is seen in table 1 above, around $87 \%$ engage in moderate physical activity, while $54 \%$ engage in vigorous physical activity.

\section{Alcohol Consumption}

The second health behavior we assess is alcohol consumption. The burden of alcohol consumption is well-known; it is one of the largest avoidable risk factors and contributes substantially to the global burden of disease (responsible for almost $4 \%$ of total mortality (Rehm et al., 2009)). Much of recent work now considers alcohol an economic problem and not just a public health issue (Baumberg, 2006). Therefore, understanding whether retirement affects alcohol consumption in anyway may provide policy makers (both in the field of labour economics and public 
health) with interesting insights. For alcohol related behavior we analyze four different indicators that precisely report drinking habits of the elderly. The first is how often in the last three months a person consumed alcohol with responses ranging from 1 "Not at all in the last three months" to 7 "Almost every day". The second indicator relates to how many drinks in a day a person consumes and is measured on a continuous scale. As shown in table 1 above, while $26 \%$ report no drinking at all in the last three months, around $22 \%$ report that they drink every day. As for the drinking intensity, table 1 shows that the average number of drinks per day is roughly three. The third indicator reports if the respondent had an excessive drinking problem at any time. Only about $3 \%$ respond in the affirmative to this question. Following the standard definition in the literature (Cawley \& Ruhm 2011; Naimi et al. 2003), we also generate a binge drinking indicator which equals 1 if the respondent reports having 5 drinks or more on a single occasion. Around 8\% report positively for binge drinking.

\section{Smoking}

One of the biggest public health and economic concerns of recent times is tobacco consumption. It is shown to be a risk factor for several diseases many of which such as cardiovascular diseases, respiratory diseases etc. impose a heavy burden on health care systems worldwide (Levenson, 2002; Leidl et al., 2000). It has not only health related costs but also indirect costs due to loss of productivity (Leidl et al., 2000). Smoking therefore, has a huge economic, as well as welfare impact on society. In this paper smoking behavior is captured by three variables. First, the respondent is asked if he/she currently smokes. Around $26 \%$ report to be current smokers. The second and third variables are with respect to the intensity of smoking where respondents are asked to specify the average number of cigarettes smoked a day which is measured on a continuous scale ${ }^{5}$. The average number of cigarettes smoked per day is about 1.4 when including the non-smokers ${ }^{6}$ and approximately 16.5 when exclusively focusing on the smokers. All the descriptive statistics can be seen in Table 1 above.

\subsubsection{Health Status}

\section{Subjective Health Status}

To provide an overall assessment on how the potential changes in the above health behaviors affect ones health, we also analyze the effects of partner's and own retirement on subjective health. Self-reported health status is measured on a 5-point scale ranging from 1 "Poor Health" to 5 "Excellent Health". While around $8 \%$ of the estimation sample report to be in poor health, the biggest share of old people (39\%) report to be in good health. Finally, roughly $9 \%$ indicate currently having an excellent health status (see table 1).

\footnotetext{
${ }^{5}$ The first smoking intensity variable includes zeros for the non-smokers and the second one excludes them.

${ }^{6}$ Note that we replace missing values on this variable with zero for those that reported "currently non-smoker" in the smoking participation question. We keep missing for those that reported "yes" for "current smoker" but did not report on the number of cigarettes.
} 


\subsection{Treatment Variable}

\section{Retirement and Eligibility Threshold}

Retirement status as explained earlier is determined on the basis of a self-reported indicator related to the current job situation at the time of the survey. The survey collected detailed information on key variables related to the age of the individuals and the interview, such that we have data on the month and year of birth of each respondent and also the month and year in which the interview took place. We are therefore able to precisely estimate a continuous measure of age of the individual at the time of the interview. This is crucial to the econometric design since age is our forcing variable and (partly) determines the treatment status.

Although most of the countries implemented substantial reforms to their pension systems, many of these are aimed at increasing coverage, improving adequacy of retirement incomes, and ensuring financial sustainability among others. Increasing the retirement age is only one aspect of systems reforms, although the most sensitive politically (OECD, 2013). Table 2 below shows the official retirement ages for the countries used in this analysis. We can see that the official retirement age for women is lower than men in almost all countries. There is little variation in the retirement ages across countries and between the years of the survey. Female retirement age increased from 63 to 64 between 2004 and 2006 for Belgium and Switzerland. Most countries gradually increased the official retirement age. Belgium increased it from 63 (2004) to 64 (2006) to 65 (2009) for women. Since January 1996, the official retirement age for Czech Republic has been gradually increasing by 2 months per year for men and 4 months for women with a target age of 63 that was to be reached by 2012. France aims to increase the retirement age to 67 by 2022. A trend towards the same retirement age for men and women can in general be observed in most countries now. Details on the eligibility thresholds and changes in retirement ages can be obtained from the Social Security Programs Throughout the World Survey (SSPTWS) available from the U.S. Social Security Administration and OECD Pensions at a glance ${ }^{7}$. Since some individuals retire earlier than the official retirement age due to various reasons, we accommodate this by using a fuzzy regression discontinuity which allows for a discrete increase in the retirement probability. As seen in table 2 below, retirement age for men is 65 years in all countries except for Czech Republic (61) and France (60), while that for women is generally lower than men and ranges from 60 up to 65 . Moreover, the summary statistics in table 1 show that our sample consists of $57 \%$ retirees.

- Insert table 2 about here -

\section{Identification Strategy}

The main purpose of this paper is to identify the causal effect of spousal retirement on the health behavior of the other partner. Any identification strategy that successfully aims at isolating such causal effects needs to address the endogeneity in the partner's retirement status. Endogeneity

\footnotetext{
${ }^{7}$ The retirement age data can be obtained from http://www.socialsecurity.gov/policy/docs/progdesc/ index.html [Last accessed 10 May 2015] \& OECD Pensions at a Glance.
} 
in our context could arise due to two sources: First, omitted variable bias, e.g., the possibility of grandparenting may make one more likely to consider retirement (positive correlation) and moving closer to grandchildren may decrease smoking (negative correlation) implying a negative bias in the estimated retirement effects. Second, reverse causality, i.e., the decision to retire may depend on health and subsequent health behavior. As a direct consequence, standard regression techniques lead to biased and inconsistent coefficient estimates. In this paper, we address these endogeneity issues by using a fuzzy regression discontinuity design exploiting the discontinuity in the retirement rates at the country-specific official retirement ages.

\subsection{Fuzzy Regression Discontinuity Design}

The Regression Discontinuity (RD) design is based on the idea that the researcher has precise knowledge about institutional rules that determine treatment. In that, the individual treatment status is determined by an assignment or forcing variable. If the forcing variable crosses a known cutoff value $c$, treatment is (partially) switched on or off. Validity of the design crucially depends on the agent's inability to precisely control/manipulate the forcing variable near $c$ and thus randomly assigning them into a treatment and control group (Lee \& Lemieux, 2010).

In the European countries under consideration in this paper, retirement eligibility does not necessarily imply that individuals are actually retired. Thus, the discontinuity in the probability of going into retirement is smaller than $100 \%$ at the official retirement age because retirement is not mandatory ("imperfect compliance"). This setup naturally leads to a fuzzy RD design where partner's age is the forcing variable $\left(X_{i}^{p}\right)$ that partially determines spousal retirement. As shown in the previous literature, all pension schemes in Europe provide strong incentives to retire at the official retirement ages and thus determining the timing of retirement (Coe \& Zamarro, 2011; Zissimopoulos et al., 2007). Estimation of the spousal retirement effects essentially amounts to using the discontinuity in the retirement probability as an instrumental variable for partner's retirement status. We apply Two-Stage Least Squares (2SLS) to estimate parametric equations of the form:

$$
\begin{aligned}
Y_{i} & =\alpha+\tau_{1} D_{i}^{p}+\beta_{1} \widetilde{X_{i}^{p}}+\beta_{2} \widetilde{X_{i}^{p}} D_{i}^{p}+\tau_{2} D_{i}+\beta_{3} \widetilde{X_{i}}+\beta_{4} \widetilde{X_{i}} D_{i}+\lambda_{t}+\Lambda_{i}+\varepsilon_{i} \\
D_{i}^{p} & =\gamma+\gamma_{1} \widetilde{X_{i}^{p}}+\delta_{1} T_{i}^{p}+\delta_{2} \widetilde{X_{i}^{p}} T_{i}^{p}+\lambda_{t}+\Lambda_{i}+v_{i} \\
D_{i} & =\gamma+\gamma_{1} \widetilde{X_{i}}+\delta_{1} T_{i}+\delta_{2} \widetilde{X_{i}} T_{i}+\lambda_{t}+\Lambda_{i}+u_{i}
\end{aligned}
$$

where $i$ indexes individual $i$ and the superscript $p$ represents partner; $Y_{i}$ is an indicator for individual $i$ 's health behavior as described in section $3.2 ; D_{i}^{p}$ is the indicator for partner's retirement status of individual $i$; $D_{i}$ is the corresponding own retirement indicator; $\widetilde{X_{i}^{p}}=\left(X_{i}^{p}-c\right)$ is individual $i$ 's partner's age centered at the country-specific retirement age $c ; \widetilde{X}_{i}=\left(X_{i}-c\right)$ is own age centered at the official retirement age. We instrument spousal and own retirement using the respective retirement age threshold crossing indicators $T_{i}^{p}=1\left[\widetilde{X_{i}^{p}} \geq 0\right]$ and $T_{i}=1\left[\widetilde{X_{i}} \geq 0\right]$ which equal one if (partner's) age exceeds the official country-specific retirement age. In addition, we use interaction terms of those indicators with centered (partner's) age $\left(\widetilde{X_{i}^{p}} T_{i}^{p}\right.$ and $\left.\widetilde{X_{i}} T_{i}\right)$ as additional instruments. Furthermore, $\lambda_{t}$ are year and $\Lambda_{i}$ country dummies capturing year- and country fixed-effects. Finally $\varepsilon_{i}, v_{i}$ and $u_{i}$ are idiosyncratic error terms. 
Equation (1) shows that the effects of spousal and own retirement are captured by the parameters $\tau_{1}$ and $\tau_{2}$. Equations (2) and (3) on the other hand are classical first-stage equations linking the endogenous treatment variables $D_{i}^{p}$ and $D_{i}$ to the respective set of exogenous variables and the instruments. Note that we also include own retirement in all our model specifications allowing us to further isolating the effect of spousal retirement as couples tend to make joint retirement decisions rendering own retirement a possible source of omitted variable bias (Banks et al. 2010; Coile (2004)).

Further, note that an analogous first-stage equation to equations (2) and (3) is constructed for $\widetilde{X_{i}^{p}} D_{i}^{p}$ and $\widetilde{X_{i}} D_{i}$ using the same set of instruments described above. Our model specification provides an adequate representation of the functional form of the relationship between partner's age and our outcome variables and the retirement rate as we allow for different slopes on both sides of the retirement cutoff through the inclusion of the interactions of partner's age with spousal retirement and the instrument (Angrist \& Pischke 2008). In line with the more recent findings by Gelman \& Imbens (2014), we do not include higher order (third, fourth, or higher) polynomials of the forcing variable since in general, $\mathrm{RD}$ estimates have proven to be sensitive and conventional inference tends to perform poorly in these settings.

As in any standard IV framework, the estimated treatment effects have to be interpreted as local average treatment effects (LATE). That is, we estimate the average treatment effect for those individuals who exit the labor market into retirement due to being eligible for oldage pensions, i.e., those crossing the official country-specific retirement age ("retirement age compliers"). In our analysis, the group of compliers is substantial in size ${ }^{8}$ since many people actually retire at the official retirement age which in turn emphasizes the importance of the estimated retirement effects presented below. Moreover, to shed light on the distribution of complier characteristics, we compute compliers' characteristic ratios, i.e., the ratio of the firststage effect conditional on a specific characteristic relative to the overall first-stage (Angrist \& Pischke 2008). Our analysis shows that retirement age compliers are more likely to be women, married and more educated than the average old person in the estimation sample. In addition, the retirement compliers are also less likely to be in good health than the average old adult. Before presenting the estimated partner's retirement effects, we provide more evidence for the validity of the fuzzy RD design in our context.

\section{Discontinuity in the Retirement Rate}

To give further motivation for the fuzzy RD framework in our context, figure 1 below gives a graphical representation of the first-stage effects for partner's and own retirement. The figure shows the average share of retirees in bins of quarters of age ${ }^{9}$. The scatter plots are overlaid with local polynomial smooths (solid dark blue lines) on both sides of the discontinuity. The graphs clearly indicate that less than $50 \%$ of individuals are retired two or more years before reaching the official retirement age. After that, the probability of going into retirement increases rapidly: In the last year before the age cutoff, between 50-60\% of individuals are retired indicating the cases of early retirement. Above the official retirement threshold, the share of retirees increases sharply by at least 20 percentage points indicating a discontinuous jump in the probability of

\footnotetext{
${ }^{8}$ The size of the complier group equals the first-stage effect; in this analysis we have $\hat{\delta}_{1}=0.25$

${ }^{9}$ The age variable is centered by subtracting the country-specific retirement age $c$.
} 
going into retirement at the country-specific retirement ages. This means that individuals below the cutoff have a significantly lower probability to retire than those just above the discontinuity. As mentioned above, the discontinuity simply reflects the fact that all retirement systems in Europe provide strong incentives for employees to go into retirement once they reach the official retirement age. The fact that we actually observe a steep ascent in retirement indicates that people around the cutoff actually respond to such incentives. Since individuals cannot manipulate their age and therefore have no precise control over the assignment variable, it follows naturally that those below form a natural control group for those above.

— Insert figure 1 about here -

Furthermore, the discontinuities clearly satisfy instrument relevance since the first-stage $F$ statistics are 437.03 and 201.65 in both the models with and without a flexible age function respectively (see table 3 below). We find that the partner's retirement rate jumps up by about 24 percentage points when partner's cross the official retirement age and the own retirement rate by about $34-35 \%$ when individuals themselves cross the official retirement age coinciding with the graphical evidence in figure 1. Before moving on to the analysis of retirement effects, we present further RD validity checks.

— Insert table 3 about here -

\subsection{RD Validity Checks}

The key identifying assumption in the RD framework is the inability of individuals to precisely control the assignment variable near the threshold. As a consequence of this assumption, all observed and unobserved characteristics should be balanced around the cutoff and treatment is "as good as randomly assigned". In other words, individuals below the age cutoff represent a valid control group for those just above the threshold and any comparison between groups reveals the local causal effects of interest (Lee \& Lemieux, 2010).

\section{Checks for Local Random Assignment}

As a first validity check for local random assignment, we investigate the density of the forcing variable. Figure 2 in Appendix A1 shows the histogram of age overlaid with a kernel density estimate. Inspecting the density graph suggests no manipulation of the assignment variable since it appears to be smooth around the threshold thus reinforcing the validity of the RD approach used in this paper ${ }^{10}$.

\section{Inspection of Baseline Covariates}

As an additional validity check we compare predetermined individual characteristics just below and above the official retirement age to see whether they are locally balanced around the cut-

\footnotetext{
${ }^{10}$ In addition, we conducted the more formal McCrary (2008) test which also provides no evidence for a significant discontinuity in the distribution of age at the retirement threshold.
} 
off. In fact, if treatment is locally randomized then individuals around the retirement threshold should not differ substantially in observable and unobservable characteristics. Figure 3 in Appendix A2 shows the scatter plots of years of education, share of men and the number of children overlaid with local polynomial smooth plots (dark blue lines) in a window of \pm 3 years around the retirement cutoff. The graphs clearly indicate no significant discontinuity in any of the baseline covariates at the threshold pointing towards local random assignment. Overall, the RD validity checks support our identification strategy and provide no evidence for violations of the key underlying assumptions. We conduct additional placebo tests with respect to predetermined variables which are discussed in detail later.

\section{Results}

First, we present and discuss the results of the effect of partner's retirement on each of the health behaviors. Then, we discuss the results of own retirement on each of the health behaviors placing it in context of the findings from previous literature on the topic. Next, in order to examine what the effects on health behavior mean for overall health, we assess the net effects of partner's and own retirement on health. We present the estimated spousal and own retirement effects for two model specifications: in model 1, we implement the most basic fuzzy RD estimator which uses only the retirement threshold crossing indicators as instruments for own and partner's retirement ${ }^{11}$. In our full specification (model 2 ) which corresponds to the specification described in the identification strategy section 4.1 above, we extend model 1 by using interactions of spousal retirement with centered age and own retirement with centered age $\left(\widetilde{X_{i}^{p}} D_{i}^{p}\right.$ and $\left.\widetilde{X_{i}} D_{i}\right)$ as additional endogenous variables and interaction terms of the retirement threshold crossing indicators with centered age $\left(\widetilde{X_{i}^{p}} T_{i}^{p}\right.$ and $\left.\widetilde{X_{i}} T_{i}\right)$ as additional instruments. Our parametric RD estimates are complemented by graphical evidence showing the reduced-form effects for all the health behaviors and subjective health (see figures $4-6$ in Appendix A4). In addition, the parametric estimates of the reduced-form effects for spousal and own retirement corresponding to our estimates of model 1 in tables 4 and 5 can be found in table 8 in Appendix A3.

\section{Partners's and Own retirement effects - Health Behaviors}

\section{Moderate and Vigorous Physical activity}

Table 4 gives an overview of the fuzzy RD estimates in our baseline specification, as well as the full specification allowing for more flexible functional forms of centered age. As seen in both specifications, we find a negative effect of partner's retirement on moderate physical activity which is significant at a $10 \%$ level. The estimated effect suggests that the likelihood of engaging in activities requiring moderate levels of energy decreases by about 5 percentage points pointing toward a negative externality of spousal retirement on the other partner. The effect is sizeable when considering that the baseline probability of engaging in moderate physical activities is

\footnotetext{
${ }^{11}$ We present this just-identified fuzzy RD estimator because it has the virtues of transparency and good finitesample properties (Angrist \& Pischke, 2008).
} 
on average about $86 \%$ in the three years before reaching the official retirement age ${ }^{12}$. As for the spousal retirement effects on vigorous physical activity, our RD estimates show that there is no effect on engaging in vigorous physical activities in both specifications ${ }^{13}$. Note also that the first-stage effects are highly significant pointing towards instrument relevance as the first stage $F$-statistics of 437.03 in the first and 201.65 in the second specification clearly exceed the Stock-Yogo critical values at any common significance level (see table 3).

With respect to the effect of own retirement, we find a positive and significant effect of own retirement on moderate and vigorous physical activity in both model specifications indicating an increase in the probability of engaging in activities requiring moderate and vigorous levels of energy by about 6 percentage points. Again, the estimated effects are sizeable given that on average only $54 \%$ of the elderly engage in vigorous physical activities in the three years before reaching the retirement threshold. Moreover, these results are in line with some of the most recent evidence on the effect of own retirement on physical activity. In a sample of German retirees, Eibich (2015) finds a sizeable increase in the likelihood for retirees to regularly participate in physical activity, and also an increase in time invested in household chores that require physical efforts. The latter indicator is more similar to our moderate physical activity variable which involves activities such as gardening or going on a walk.

\section{Smoking}

Table 4 also presents the estimated partner and own retirement effects for smoking behavior where we focus on whether the individual currently smokes and the number of cigarettes smoked per day ${ }^{14}$. Our RD estimates provide no evidence for an effect of intra-household retirement externalities on the likelihood of smoking and the number of cigarettes smoked per day when including the non-smokers as we do not find a statistically significant coefficient of the effect of spousal retirement. However, we find a positive and highly significant effect of spousal retirement on the daily number of cigarettes smoked when excluding the non-smokers pointing towards the presence of retirement externalities among the smokers. The estimated spousal retirement effects imply that the already smokers who smoked on average about 16-17 cigarettes per day in the three years prior to the cutoff, start to smoke more than one package a day once their partner goes into retirement. In other words, the results show that there is no effect on smoking initiation but there is a positive effect on existing smoking behavior. Furthermore, unlike Insler (2014) and Eibich (2015), we do not find a significant effect of own retirement on both current smoking and the number of cigarettes smoked.

- Insert table 4 about here -

\footnotetext{
${ }^{12}$ In fact, the average share of the elderly engaging in moderate physical activities is also $86 \%$ over the whole estimation sample.

${ }^{13}$ For the sake of brevity, we refrain from showing the coefficient estimates on the running and control variables.

${ }^{14}$ We distinguish between two measures of cigarettes smoked per day: one including the non-smokers and the other without the inclusion of non-smokers.
} 


\section{Alcohol Consumption}

Table 5 below presents partner's and own retirement effects on individual drinking behavior which we analyze along three dimensions: The frequency of alcohol intake, the intensity of alcohol consumption (number of drinks and binge drinking) and whether a person reports to have a drinking problem. Our results provide strong evidence for a sharp increase in the frequency of alcohol intake as a response to partner's retirement. In fact, our RD estimates indicate a significant increase by roughly one to two categories on our alcohol frequency variable in both specifications. Given that the typical individual in the sample reports to drink once or twice a week, this effect is sizeable as spousal retirement moves that person's alcohol intake to drinking at least three or four times a week. A similar response can be observed as a reaction to own retirement where own retirement increases alcohol intake significantly. Our findings on own retirement effects again coincide with the existing literature which shows a general increase in alcohol consumption after retirement (Zins et al., 2011). Eibich (2015) finds that retirement increases the probability of alcohol consumption, however he does not measure the quantity of alcohol consumed. In our data, we are able to assess the effect of partner's and own retirement on the amount consumed as well.

Similar conclusions can be drawn when looking at the intensity of alcohol consumption as measured by the number of alcoholic beverages consumed per day and binge drinking. Our RD estimates point toward an increase of more than one additional drink per day as a response to spousal retirement. This effect is again substantial given that the average individual in our estimation sample consumes about three alcoholic beverages per day in the three years prior to reaching the official retirement age, therefore moving their alcohol consumption significantly closer to what is considered binge or heavy drinking which is known to cause severe adverse health effects (e.g. Courtney \& Polich, 2009). We also find a significant positive effect on binge drinking directly. Extending Eibich's (2015) analysis on the quantity of alcohol consumed, we find no effect of own retirement on the quantity of alcohol consumed. As for the effects on having a drinking problem, the sharp increase in alcohol consumption directly carries over onto the likelihood of reporting to have a drinking problem. In particular, we find that the probability of having a drinking problem significantly increases by 10 percentage points when the spouse enters retirement.

Previous literature focusing on the effect of own retirement has found strong effects on drinking problems. Ekerdt et al. (1989) suggest that retirees were more likely to report periodic heavy drinking and drinking problems. Zins et al. (2011) find that retirement may increase the risk of excessive alcohol consumption at least temporarily. Bacharach et al. (2004) find that individuals opting to retire were twice as likely to engage in periodic heavy drinking. More recently, Eibich (2015) reports a 12 percentage point decrease in the probability of abstaining from alcohol. Similar to these papers, we also find a huge increase in drinking behavior albeit in response to partner's retirement. An increase in both, the frequency and amount consumed (binge drinking) translates into a strong effect on having a drinking problem.

In fact, salient life events have shown to exacerbate drinking (Merrick et al., 2008; Moore et al., 2005); retirement has been touted as a significant life transition event that affects drinking behavior and can even lead to alcohol misuse (Bamberger, 2015). While the attention is usually 
on own retirement, spousal retirement is also an important life transition event. Different theories explain the retirement-drinking relationship ranging from stress related mechanisms to post-retirement adjustments (see Bamberger (2015) for a detailed discussion of these). An important theory that explains drinking behavior with respect to retirement points towards network and social effects. As mentioned earlier in the paper, externalities of partner's retirement could exist due to exogenous/endogenous social effects. Alcohol use is likely to be socially motivated among other reasons (Sacco et al., 2014). Several studies that assess drinking problems in retirement communities find these to be largely due to social reasons where drinking becomes an important part of the leisure sub-culture. Regular drinking has been found to be common in retirees and this is primarily due to social activities (Alexander \& Duff, 1988). Spousal retirement provides an individual the opportunity to socialize to a greater extent than before especially if retirement is recent where periods of celebration are likely to exist. As Zins et al., (2011) point out, excessive drinking may be a temporary phenomenon - we further discuss this point below.

— Insert table 5 about here -

\section{Partners's and Own retirement effects - Subjective Health}

After assessing the effects on different health behaviors, a natural next step is to assess how these translate into desirable or undesirable health outcomes. If we consider an increase in alcohol intake and a decrease in moderate physical activities due to partner's retirement a disinvestment in health, then the expected impact on health should be negative. Indeed, we find that partner's retirement has a significant negative effect on self-assessed health (see table 6). With respect to own retirement, the picture seems somewhat unclear since we find that it increases alcohol consumption but at the same time also makes one more likely to engage in moderate and/or vigorous physical activities. In this case, while one behavior may reduce health, the other is an investment in health and hence health improving. We find that overall, own retirement has a significant positive effect on subjective general health (see table 6). This result is in accordance with much of the previous literature that finds a positive effect of retirement on health (see Coe \& Lindeboom, 2008; Neumann, 2008; Johnston \& Lee, 2009; Coe \& Zamarro, 2011; Eibich, 2015 among others) while it contrasts others that find adverse health effects of retirement (see for example Dave et al., 2008; Bamia et al., 2008; Bonsang, 2012). The results of retirement on health are therefore interesting since we find such opposing effects with respect to own and partner's retirement and the question arises as to which effect dominates. If an individual's partner is retired but the individual himself is not, then the negative effects may play out for such individuals without the positive effects of own retirement being seen. Which effect dominates will also largely depend on how far in time these continue to exist. Since our RD design requires a short window around retirement for proper identification of the causal effects at hand, these effects are only short-term. 


\subsection{Effect Heterogeneity}

As mentioned in the previous section, the effects of own and partner's retirement on health may play out differently for different individuals. To shed more light on this issue we explore the question whether spousal retirement has differential effects by focusing on heterogeneity between those with and without a retired partner, already smokers and drinkers and by gender. As a first step, it may be plausible to presume that we do not find any overall retirement externalities on physical activity because roughly $50 \%$ of the sample are not retired themselves so that they are lacking the additional time or energy to be more physically active once their partners go into retirement. In other words, the positive effect of spousal retirement on moderate and vigorous physical activity may manifest itself only for those that are retired themselves. Our rationale is that we would expect retired couples to spend more time together on leisure activities compared to couples where at least one partner is still in the labor market. On top of that, retired couples are more likely to share the work load at home which leaves them with more time to engage in leisure activities. We test for this hypothesis by analyzing partner's retirement effects separately for retired and non-retired respondents. We do not find support for any heterogeneous effects on physical activity as the spousal retirement effects are not significantly different between those with and without an already retired partner as shown in table 7 below.

Similarly for alcohol consumption, we would expect that a retired individual would both drink more often and possibly consume larger amounts of alcoholic beverages since he/she does not have to worry about employment issues such as being late for work, missing days of work entirely due to excessive drinking, and worry about reduced productivity. Therefore, when the partner retires, there is a greater possibility of social drinking with the partner and hence we would expect an increase in alcohol consumption. There may also be compensated effects such that utility from own leisure activities increases with the partner being involved in the leisure activity as well. As Hurd (1990) mentions it, husband's and wives' retirement may be complements, such that in our case we may find retirement effects only if both partner's are retired which allows them to indulge in activities such as social gatherings and lead to an increase in alcohol consumption. While the results in table 7 show that the coefficients within the subsample of retirees are slightly larger in magnitude in general, the differences in coefficients are not statistically significant as the confidence intervals clearly overlap between retirees and non-retirees. Therefore our results do not point towards systematic effect heterogeneity between those with and without a retired partner.

Applying the same reasoning to tobacco consumption, table 7 also does not provide evidence for effect heterogeneity of partner's retirement between those with and without a retired partner: partner's retirement effects overlap at the extensive but also the intensive margin pointing towards an insignificant difference in effects among the retirees and non-retirees. However, we would also expect heterogeneity in smoking behavior with respect to the smoking status of the retiring partner. A priori, the effect of partner's retirement on smoking should be significant only if the partner himself is a smoker. This may be due to strong complementarities in smoking where greater utility is derived out of the activity when the other partner also does it (Banerjee, 1992). Since both partner's now also have a greater amount of time to spend with each other, they may involve more in such complementary behavior. In line with this expectation, we find 
evidence for a significant increase in the cigarettes smoked per day as a response to partner's retirement among those with an already smoking partner (see last column in table 4).

Furthermore, one could easily imagine that already drinkers might be more likely to increase both their drinking frequency and also intensity once they themselves go into retirement or their partner joins them. On the other hand, we would expect that light- or non-drinkers do not significantly adjust their alcohol consumption as starting new behaviors is unlikely at an advanced age. A separate analysis shows that the drinkers indeed significantly increase their drinking frequency as a response to partner's and own retirement. However, we do not find evidence for a significant increase in the drinking intensity as measured by the number of drinks consumed per day. In addition, our results provide evidence against the hypothesis that the elderly are unlikely to change already existing drinking behaviors: among the lightor non-drinkers, we find significant effects of own and spousal retirement on both the drinking frequency and intensity ${ }^{15}$.

— Insert table 7 about here -

We also investigate differences in retirement effects by gender of the retiring partner. As Szinovacz \& Davey (2004) point out, high marital quality is particularly important for well-being in the stressful period of retirement. Moen et al., (2001) show that husband's retirement leads to non-retired women experiencing lower quality of marriage. Similarly, Kulik (1999) argue that retirement increases men's dependence on women's resources triggering changes in marital roles. Smith \& Moen (2004) find that husbands are more satisfied with wife's retirement but the vice-versa case does not hold. Retirement satisfaction is positively correlated with subjective health. Overall, this means that the male partner's retirement affects the female partner's health negatively while the female partner's retirement is good for the male partner's health (Szinovacz \& Davey, 2004). However, if the husband fails to share responsibility of household work, marital conflicts due to issues around division of labour may arise leading to decreases in health for the couple. We assess such heterogeneity and find results in accordance with the above literature. While retirement of the wife does not show any effect on the health of the husband, retirement of the husband has a significant (at a 10\% level) effect on wife's subjective health status. These results compliment recent findings of Bertoni \& Brunello (2017) that show a negative effect of male retirement on female mental health in Japan.

Finally, it is important to consider post-retirement dynamics of the effects in question since it may take time for some effects to show or if they do show, they may only be temporary. Coe \& Lindeboom (2008) for example study such dynamic health effects of retirement and report only temporary effects on health. Gorry et al. (2015) on the contrary find significant long-term health improving effects of retirement. Our methodological approach requires the comparison of individuals around the cutoff (i.e. in a small window around the retirement cutoff) since these are likely to be similar to each other conditional on RD assumptions being satisfied. Owing to the methods and data limitations, we are unable to perform an ideal long-term analysis of the effects of retirement on health and the different health behaviors. We leave this avenue open for future research. However, we also assess heterogeneity with respect to whether the individual

\footnotetext{
${ }^{15}$ These additional results are available upon request.
} 
retires closer to the partner or not. We re-estimate the models using only those individuals that have been retired for more than 3 years and upto 6 years. We do not find significant effects of partner's retirement on most of the outcome variables. Smoking being difficult to quit seems to show effects even after 3 years of partner's retirement but only for individuals whose partners are smokers as well. The effects on alcohol consumption are not significant anymore with one exception: we still find a statistically significant effect on the indicator for frequency of alcohol intake.

\section{$6 \quad$ Further Checks}

\subsection{Robustness Checks}

In the last section we showed that our findings are robust to different model specifications. We further assess the robustness of our results with respect to different window sizes around the retirement cutoff, non-linear functional forms in the relationship between age and the outcome variables and the retirement rate, the inclusion of further control variables and variations in the estimation sample, as well as different definitions of retirement. All robustness checks can be found in Appendices A5 - A7.

Tables 9 and 10 in Appendix A5 present the resulting partner's and own retirement effects when considering window sizes of \pm 1 years, then \pm 2 years and finally \pm 5 years of partner's age around the retirement cutoff. Using different window widths ensures that the results do not entirely depend on the correct specification of the functional form of the forcing variable or that they are driven by data points that are far away from the discontinuity (Angrist \& Pischke, 2009; Lee \& Lemieux, 2010). In general, the results in tables 9 and 10 almost perfectly replicate our main findings as we find significant partner's retirement effects on subjective health, moderate physical activity, alcohol frequency, drinking intensity (drinks per day and binge drinking) and having a drinking problem and no effects on vigorous physical activity and smoking. Regarding own retirement, we find a positive and significant effect on subjective health, moderate and vigorous physical activity and alcohol frequency across all window widths. Not surprisingly, the coefficients using a discontinuity sample of \pm 1 around the cutoff are estimated with much less precision as they are constructed using only a fraction of the full data. Still, the estimated local average treatment effects are qualitatively the same and therefore lead to the same conclusions as discussed above.

To rule out potential biases in the estimated retirement effects due to misspecification of the functional form of the relationship between age and our outcome variables and the retirement rate, we re-estimate all the models including (partner's) age squared and interactions of own (partner's) age squared with own (partner's) retirement as additional endogenous variables. As additional instruments we use the squared age terms with the threshold crossing indicators and the resulting retirement effects can be found in table 11 in Appendix A6. Overall, the inclusion of an even more flexible functional form of the forcing variable leads to almost identical results as above.

Similar to Godard (2015), to ensure that the significant effects of partner's retirement on an individual's behavior are not driven by a specific country, we exclude countries one at a time 
from our analysis. We also include further baseline covariates as controls (see Appendix A7). The results are both qualitatively and quantitatively robust to these checks.

An important concern in the interpretation of the results as 'externalities associated with spousal retirement' looms around the specifics of the retirement decision itself. Hurd (1990) finds that husbands and wives tend to retire at the same time. Thus, while there maybe an externality effect, couples might have jointly optimally timed their retirement. Economic models of family decisionmaking such as the marriage market (cooperative type) models show that men and women meet in the marriage market and sort marital partners based on similar preferences and tastes. Such assortative mating itself could lead to a correlation in the retirement timing of both partners (Woolley, 1990; Hurd 1990). Intertemporal models argue decisions made in one period might affect bargaining power in the future. Thus, economic variables affected by retirement such as income might push husbands or wives to time their retirement as close as possible to each other. In general, Hurd (1990) finds that husbands' and wives' retirement years are compliments. Although our RD design accounts for endogeneity with regards to the retirement decision, we perform additional sensitivity tests that account for the specifics of the retirement decision itself. First, we focus on the reason for retirement of an individual such that we exclude all those that report being retired due to ill-health. Second, since partner's may decide to jointly retire due to several reasons (health, leisure etc.) we exclude those individuals that report "retire at the same time as spouse or partner". Again, we find almost identical results as before clearly reinforcing the robustness of our findings with respect to different retirement definitions ${ }^{16}$.

\subsection{Placebo tests}

To further ensure that our results are reliable, we conduct different falsification tests. First, we generate fictitious retirement ages; the idea being similar to that in Godard (2015). We then estimate the impact of partner's retirement on all our dependent variables of interest using these fictitious retirement ages as official retirement thresholds. Using the same model specifications as above, we do not see any significant effect of partner's retirement on any of the health behaviors. Also, we do not find any significant own retirement effects in any of the models, thus confirming our empirical strategy and supporting our main results.

Second, we assess the effect of partner's retirement on certain predetermined variables that ideally should not change at retirement or at least as a result of the partner retiring at the official retirement age. We focus on 1) number of years spent in full time education, 2) gender and 3) number of children. As expected and in line with the graphical evidence in figure 3 in Appendix A2, we do not find any significant effect of partner's retirement or own retirement on any of these variables.

\subsection{Pre-retirement period effects}

It is likely that individuals may adjust their behavior even before their partner actually retires. If individuals reduce smoking or drinking to compensate for the potential decrease in income due to partner's retirement or to condition themselves to smoke or drink less in the presence

\footnotetext{
${ }^{16}$ These results can be obtained from the authors upon request.
} 
of the partner, then if anything, our results underestimate the true effects. To assess if this is the case, we check if such effects with respect to partner's retirement exist in our sample. We use the panel structure of the SHARE survey to our advantage in identifying those individuals whose partner's were not retired in the previous wave but were retired in the subsequent wave. After having identified these individuals, we assess the impact of partner's retirement in the subsequent wave on smoking, physical activity and alcohol intake in the previous wave. In short, we assess if there are any lead effects. The results indicate that there is no significant effect of partner's retirement on smoking behavior, physical activity or alcohol intake of the previous wave.

\section{Conclusion}

In this paper we explore intra-household retirement externalities by assessing the causal impact of retirement of a partner on the health behavior and health status of the other partner. Our evidence, stemming from a regression discontinuity design that exploits discontinuities in retirement created by official retirement age thresholds of countries, suggests that indeed retirement of one partner affects subjective health and health behaviors of the other partner over and above the effects of own retirement.

We find that partner's retirement decreases moderate physical activity and increases alcohol consumption (both frequency and amount). Overall, we find that partner's retirement has a negative impact on subjective health. Own retirement on the other hand, increases physical activity, has no impact on smoking behavior, and only increases the frequency of alcohol intake. Overall, own retirement has a positive effect on subjective health status.

Further, our results provide evidence that spousal retirement increases smoking among the already smokers. The results therefore show that while own retirement has positive effects on health, spousal retirement has negative implications on the individual health status. The negative effect of spousal retirement on health is therefore mediated through the increase in undesirable health behaviors such as alcohol intake, smoking, and a decrease in physical activity. Similarly, the positive effect of own retirement is mediated through an increase in desirable health behaviors such as engaging in moderate and vigorous physical activity. With respect to gender related heterogeneity, we find that while female retirement has no impact on male health, male retirement has a significant negative effect on their wife's subjective health status.

After having identified these effects, a natural question that arises is why do these results matter and how useful they can be in informing policy decisions. Ageing of the baby boomers has resulted in a demographic shift in the OECD countries where the proportion of population moving closer to retirement or already retired has increased substantially (Johnston \& Lee, 2009; Bonsang et al., 2012). Further, increases in life expectancy have increased the duration of life lived in the retired state for an individual (Bonsang et al., 2012). A large number of individuals are moving and are expected to move out of the labor market and into retirement, and a large number of countries are aiming to increase or decrease retirement ages and implement different policies either to economically strengthen the aged population or to control public finances (Charles, 2002; Behncke, 2010; Celidoni et al., 2013; Cribb et al., 2014). 
The adverse health effects, as seen with the negative effect on health can likely result in significant costs to the healthcare system. Since the analysis is based on European data it is important to note that these costs will be largely borne by the public system since health systems in these countries operate on the prinicple of universal coverage and are predominantly social insurance based. It is important to note that even though coverage as such will not be affected after retirement, contributions towards health care will vary from country to country. Some countries are mildly regressive in contributions while others may provide exemptions to pensioners. Individual contribution rates will therefore differ post-retirement (Saltman et al., 2004). If contributions are lower post-retirement but the health burden increases it is in the interest of policy makers to carefully consider retirement legislation changes. When partners consider joint retirement, this effect may even be aggravated. Further, retirees already live on reduced income (ceteris paribus) and hence an increase in expenditure on alcohol may drive down consumption on other healthier food or activities. As such there may be a double negative effect. However, at the same time the results also show that there is an increase in physical activity in response to own retirement. Own retirement is therefore health improving as seen with the effects on subjective health. Raising the retirement age may delay the beneficial effects of physical activity in response to own retirement but it may also delay the harmful effects arising due to alcohol consumption in response to own and partner's retirement. In this case, health promotion strategies for the elderly and couples nearing retirement or already retired could exclusively target reduction of alcohol consumption. Lastly, more recently there is a move towards converging male and female retirement ages. If the negative health effects of spousal retirement can be compensated with the positive health effects of own retirement, then converging male and female retirement ages seems to be a logical step in addressing any health related issues. The paper therefore raises important points and provides new avenues to researchers that are interested in analyzing such trade-offs. If anything, it is at least clear that both the costs and benefits arising due to retirement not just on the individual but also on others affected by the retirement decision of the individual must be internalized when framing retirement policies.

This is the first paper to the best of our knowledge that highlights causal behavioral externalities of spousal retirement and thus imparts interesting new insights for retirement reforms. The paper highlights the role of such external policies in determining risky health behaviors and thus contributes to the literature that assesses different determinants of health and health behaviors. It also advances the literature that assesses retirement effects on health in an important way. Findings from the previous literature are not only mixed and inconclusive, but also do not consider the role of spousal retirement and thus intra-household externalities. It is well established that retirement is not completely an individual decision and couples do actually time retirement. It is therefore important to consider the household instead of just focusing on one entity in it given the existence of social effects. In this paper, we consider both partner's and own retirement and show how they affect health and health behaviors. Finally, while economic outcomes are necessary in evaluating the impact of labor market changes, significant health effects of such changes also exist as shown by our results. Therefore, we also contribute to the literature assessing the impact of legislative changes such as these. 
Our analysis is largely of a short-term perspective in terms of the effects; future research on the topic could look into the long-term implications of own and spousal retirement on health behaviors. Also, understanding time use of retirees and their partners could provide additional insights into the exact mechanisms on how these externalities operate. This is interesting since the retired spouse can make time investments in the health of the partner - either by spending more time together in leisurely activities, cooking healthier food or taking good care of the health of the partner. This could give the respondent a general increase in good health which he/she can afford to 'spend' by engaging more in risky health-deteriorating behaviors such as smoking or drinking. This would then be similar to an income effect on health. Therefore, understanding how retirees spend their time post-retirement leads to interesting future research questions which have the potential to significantly improve our understanding of the diverse effects of own and spousal retirement on health and health behaviors. 


\section{Tables and Figures}

Table 1: Summary Statistics

\begin{tabular}{lccccc}
\hline \hline & Mean & S.D. & Min & Max & N \\
\hline Retired & 0.57 & 0.5 & 0 & 1 & 23598 \\
Age & 63.35 & 5.9 & 45.08 & 91.83 & 23598 \\
Male & 0.49 & 0.5 & 0 & 1 & 23598 \\
Education & 10.76 & 4.26 & 0 & 25 & 11525 \\
Number of Kids & 2.27 & 1.24 & 0 & 17 & 11732 \\
Moderate Physical Activity & & & & & \\
"More than once a week" & 0.87 & 0.34 & 0 & 1 & 23598 \\
Vigorous Physical Activity & & & & & \\
"More than once a week" & 0.54 & 0.5 & 0 & 1 & 23598 \\
Smoking behavior & & & & & \\
Smoking & 0.26 & 0.44 & 0 & 1 & 17229 \\
Cigarettes per day (incl. non-smokers) & 1.39 & 5.11 & 0 & 80 & 14096 \\
Cigarettes per day (excl. non-smokers) & 16.54 & 11.52 & 1 & 115 & 2777 \\
Frequency of Alcohol Consumption & & & & & \\
"Not at all in last 3 months" & 0.26 & 0.44 & 0 & 1 & 23587 \\
"Less than once a month" & 0.09 & 0.28 & 0 & 1 & 23587 \\
"Once or twice a month" & 0.12 & 0.33 & 0 & 1 & 23587 \\
"Once or twice a week" & 0.2 & 0.4 & 0 & 1 & 23587 \\
"Three or four days a week" & 0.09 & 0.28 & 0 & 1 & 23587 \\
"Five or six days a week" & 0.03 & 0.18 & 0 & 1 & 23587 \\
"Almost every day" & 0.22 & 0.41 & 0 & 1 & 23587 \\
Intensity of Alcohol Consumption & & & & & \\
Drinks per Day & 2.83 & 5.55 & 0 & 70 & 14927 \\
Binge Drinking & 0.08 & 0.27 & 0 & 1 & 14927 \\
Having a Drinking Problem & & & & & \\
Drinking Problem & 0.03 & 0.18 & 0 & 1 & 7744 \\
Subjective Health Status & 0.09 & 0.28 & 0 & 1 & 21854 \\
\hline "Poor" & 0.25 & 0.43 & 0 & 1 & 21854 \\
"Fair" & 0.39 & 0.49 & 0 & 1 & 21854 \\
"Good" & & & & & \\
"Very Good" & & & & & \\
\hline \hline
\end{tabular}

Notes: Summary statistics for the estimation sample using \pm 3 years of data around the official retirement age. 
Table 2: Official Retirement Ages

\begin{tabular}{|c|c|c|c|c|c|c|c|c|}
\hline \multirow[t]{2}{*}{ Year } & \multicolumn{2}{|c|}{2004} & \multicolumn{2}{|c|}{2006} & \multicolumn{2}{|c|}{2010} & \multicolumn{2}{|c|}{2012} \\
\hline & Male & Female & Male & Female & Male & Female & Male & Female \\
\hline Austria & 65 & 60 & 65 & 60 & 65 & 60 & 65 & 60 \\
\hline Belgium & 65 & 63 & 65 & 64 & 65 & 65 & 65 & 65 \\
\hline Czech Republic & - & - & 61 & 60 & 62 & 61 & 62 & 61 \\
\hline Denmark & 65 & 65 & 65 & 65 & 65 & 65 & 65 & 65 \\
\hline France & 60 & 60 & 60 & 60 & 60 & 60 & 60 & 60 \\
\hline Germany & 65 & 65 & 65 & 65 & 65 & 65 & 65 & 65 \\
\hline Greece & 65 & 60 & 65 & 60 & 65 & 62 & 65 & 62 \\
\hline Ireland & - & - & 65 & 65 & - & - & - & - \\
\hline Italy & 65 & 60 & 65 & 60 & 66 & 62 & 66 & 62 \\
\hline Netherlands & 65 & 65 & 65 & 65 & 65 & 65 & 65 & 65 \\
\hline Poland & - & - & 65 & 60 & - & - & - & - \\
\hline Spain & 65 & 65 & 65 & 65 & 65 & 65 & 65 & 65 \\
\hline Sweden & 65 & 65 & 65 & 65 & 65 & 65 & 65 & 65 \\
\hline Switzerland & 65 & 63 & 65 & 64 & 65 & 64 & 65 & 64 \\
\hline Luxembourg & - & - & - & - & - & - & 65 & 65 \\
\hline Hungary & - & - & - & - & 62 & 62 & - & - \\
\hline Potugal & - & - & - & - & 65 & 65 & - & - \\
\hline Slovenia & - & - & - & - & 63 & 61 & 63 & 61 \\
\hline Estonia & - & - & - & - & 63 & 61 & 63 & 61 \\
\hline
\end{tabular}

Source: Social Security Programs Throughout the World Survey 2015. Notes: Table 2 shows the official retirement age stratified by gender and country for years 2004,

2006, 2010 and 2012; four waves of the SHARE survey that we use. - indicates that the respective country was not part of the survey in that year. 
Table 3: First-stage effects

\begin{tabular}{lcc}
\hline \hline First-Stage Effects & & \\
\hline Dependent Variable: Partner's Retirement & & \\
\hline$I\left(\right.$ age $^{p}>$ retirement age $)$ & $0.24^{* * *}$ & $0.24^{* * *}$ \\
& $(0.01)$ & $(0.01)$ \\
$I\left(\right.$ age $^{p}>$ retirement age $) \times \widetilde{\text { age }^{p}}$ & - & $-0.04^{* * *}$ \\
& & $(0.00)$ \\
\hline Dependent Variable: Own Retirement & & \\
\hline$I($ age $>$ retirement age $)$ & $0.35^{* * *}$ & $0.34^{* * *}$ \\
& $(0.01)$ & $(0.01)$ \\
$I($ age $>$ retirement age $) \times \widetilde{\text { age }}$ & - & $-0.03^{* * *}$ \\
& \multicolumn{2}{c}{$(0.00)$} \\
\hline Country \& Year FE & Yes & Yes \\
Flexible Age Function & No & Yes \\
\hline Number of Observations & 23598 & 23598 \\
Cragg-Donald Wald F-stats & 437.03 & 201.65 \\
\hline \hline
\end{tabular}

Notes: First-stage regression results using spousal and own retirement as dependent variables. The instrument used in specification 1 is a binary indicator for (partner's) age crossing the official retirement age; specification 2 then adds an interaction of that indicator with (partner's) age. An analogous first-stage is constructed for the interactions of (partner's) retirement with (partner's) age as in the second specification. Standard errors clustered at the individual level: *** $p<0.01{ }^{* *} p<0.05$ * $p<0.1$. 
Table 4: Retirement Effects:

Physical Activity and Smoking

\begin{tabular}{|c|c|c|c|c|c|c|c|c|c|c|}
\hline \multicolumn{11}{|l|}{ Retirement Effects } \\
\hline Outcome Variable & \multicolumn{2}{|c|}{ Moderate PA } & \multicolumn{2}{|c|}{ Vigorous PA } & \multicolumn{2}{|c|}{ Smoking } & \multicolumn{2}{|c|}{$\begin{array}{c}\text { Cigarettes } \\
\text { (including 0's) }\end{array}$} & \multicolumn{2}{|c|}{$\begin{array}{c}\text { Cigarettes } \\
\text { (excluding 0's) }\end{array}$} \\
\hline Specification & $\mathrm{RD}(1)$ & $\mathrm{RD}(2)$ & $\mathrm{RD}(1)$ & $\mathrm{RD}(2)$ & $\mathrm{RD}(1)$ & $\mathrm{RD}(2)$ & $\mathrm{RD}(1)$ & $\mathrm{RD}(2)$ & $\mathrm{RD}(1)$ & $\mathrm{RD}(2)$ \\
\hline Partner Retired & $\begin{array}{l}-0.05^{*} \\
(0.03)\end{array}$ & $\begin{array}{l}-0.05^{*} \\
(0.03)\end{array}$ & $\begin{array}{l}-0.01 \\
(0.04)\end{array}$ & $\begin{array}{l}-0.00 \\
(0.04)\end{array}$ & $\begin{array}{c}0.01 \\
(0.04)\end{array}$ & $\begin{array}{c}0.02 \\
(0.04)\end{array}$ & $\begin{array}{l}-0.26 \\
(0.51)\end{array}$ & $\begin{array}{l}-0.31 \\
(0.54)\end{array}$ & $\begin{array}{c}6.57^{* * *} \\
(2.45)\end{array}$ & $\begin{array}{c}6.94^{* * *} \\
(2.62)\end{array}$ \\
\hline Retired & $\begin{array}{c}0.06^{* * *} \\
(0.02)\end{array}$ & $\begin{array}{c}0.06^{* * *} \\
(0.02)\end{array}$ & $\begin{array}{l}0.05^{*} \\
(0.03)\end{array}$ & $\begin{array}{c}0.06^{* *} \\
(0.03)\end{array}$ & $\begin{array}{l}-0.00 \\
(0.03)\end{array}$ & $\begin{array}{l}-0.00 \\
(0.03)\end{array}$ & $\begin{array}{c}0.01 \\
(0.33)\end{array}$ & $\begin{array}{c}0.05 \\
(0.34)\end{array}$ & $\begin{array}{c}2.36 \\
(1.97)\end{array}$ & $\begin{array}{c}2.18 \\
(1.91)\end{array}$ \\
\hline Country \& Year FE & Yes & Yes & Yes & Yes & Yes & Yes & Yes & Yes & Yes & Yes \\
\hline Flexible Age Function & No & Yes & No & Yes & No & Yes & No & Yes & No & Yes \\
\hline Number of Observations & 23598 & 23598 & 23598 & 23598 & 17229 & 17229 & 14096 & 14096 & 2785 & 2785 \\
\hline
\end{tabular}

Notes: Fuzzy RD estimates of the effects of partner's and own retirement for the outcomes moderate physical activity, vigorous physical activity, reporting to be a smoker and cigarettes smoked per day with one specification including the non-smokers and the other excluding them. The instruments for partner's and own retirement in model 1 are indicators for crossing the official country-specific retirement age; in model 2 interactions of the indicators with polynomials of centered age are added to the instrument set. Standard errors clustered at the individual level in parentheses: $* * * p<0.01 * *$ $p<0.05 * p<0.1$ 
Table 5: Retirement Effects:

Alcohol Consumption

\begin{tabular}{|c|c|c|c|c|c|c|c|c|}
\hline \multicolumn{9}{|l|}{ Retirement Effects } \\
\hline \multirow{2}{*}{$\begin{array}{l}\text { Outcome Variable } \\
\text { Specification }\end{array}$} & \multicolumn{2}{|c|}{ Alcohol Freq. } & \multicolumn{2}{|c|}{ Drinks } & \multicolumn{2}{|c|}{ Binge Drinking } & \multicolumn{2}{|c|}{ Drinking Problem } \\
\hline & $\mathrm{RD}(1)$ & $\mathrm{RD}(2)$ & $\mathrm{RD}(1)$ & $\mathrm{RD}(2)$ & $\mathrm{RD}(1)$ & $\mathrm{RD}(2)$ & $\mathrm{RD}(1)$ & $\mathrm{RD}(2)$ \\
\hline \multirow[t]{2}{*}{ Partner Retired } & $1.82^{* * *}$ & $1.64^{* * *}$ & $1.61^{* * *}$ & $1.58^{* * *}$ & $0.10^{* * *}$ & $0.10^{* * *}$ & $0.10^{* * *}$ & $0.10^{* * *}$ \\
\hline & $(0.17)$ & $(0.17)$ & $(0.54)$ & $(0.53)$ & $(0.03)$ & $(0.03)$ & $(0.02)$ & $(0.02)$ \\
\hline \multirow[t]{2}{*}{ Retired } & $1.04^{* * *}$ & $1.21^{* * *}$ & 0.65 & 0.50 & $0.05^{* *}$ & 0.03 & 0.00 & -0.01 \\
\hline & $(0.13)$ & $(0.13)$ & $(0.41)$ & $(0.35)$ & $(0.02)$ & $(0.02)$ & $(0.02)$ & $(0.02)$ \\
\hline Country \& Year FE & Yes & Yes & Yes & Yes & Yes & Yes & Yes & Yes \\
\hline Flexible Age Function & No & Yes & No & Yes & No & Yes & No & Yes \\
\hline Number of Observations & 23587 & 23587 & 14927 & 14927 & 14927 & 14927 & 7744 & 7744 \\
\hline
\end{tabular}

Notes: Fuzzy RD estimates of the effects of partner's and own retirement on the frequency of alcohol consumption, the number of drinks consumed per day, an indicator for binge drinking (at least 5 drinks per day) and reporting to have a drinking problem. The instruments for partner's and own retirement in model 1 are indicators for crossing the official country-specific retirement age; in model 2 interactions of the indicators with polynomials of centered age are added to the instrument set. Standard errors clustered at the individual level in parentheses: $* * * p<0.01 * * p<0.05 * p<0.1$. 
Table 6: Retirement Effects:

Subjective Health

\begin{tabular}{|c|c|c|}
\hline \multicolumn{3}{|l|}{ Retirement Effects } \\
\hline \multicolumn{3}{|c|}{ Dependent Variable: Subjective Health } \\
\hline \multirow[t]{2}{*}{ Partner Retired } & $-0.36^{* * *}$ & $-0.37 * * *$ \\
\hline & $(0.08)$ & $(0.08)$ \\
\hline \multirow[t]{2}{*}{ Retired } & $0.23^{* * *}$ & $0.24^{* * *}$ \\
\hline & $(0.06)$ & $(0.06)$ \\
\hline Country \& Year FE & Yes & Yes \\
\hline Flexible Age Function & No & Yes \\
\hline Number of Observations & 21854 & 21854 \\
\hline
\end{tabular}

Notes: Fuzzy RD estimates of the effects of partner's and own retirement on subjective health. The instruments for partner's and own retirement in model 1 are indicators for crossing the official country-specific retirement age; in model 2 interactions of the indicators with polynomials of centered age are added to the instrument set. Standard errors clustered at the individual level:

*** $p<0.01 * * p<0.05 * p<0.1$. 
Table 7: Effect Heterogeneity:

Retirees vs. Non-Retirees

\begin{tabular}{|c|c|c|c|c|c|c|c|c|c|c|}
\hline \multicolumn{11}{|l|}{ Subsample: Retirees } \\
\hline Outcome Variable & Moderate PA & Vigorous PA & Smoking & $\begin{array}{l}\text { Cigarettes } \\
\text { (incl. 0's) }\end{array}$ & $\begin{array}{l}\text { Cigarettes } \\
\text { (excl. 0's) }\end{array}$ & Alcohol Freq. & Drinks & Binge Drinking & Drinking Problem & Health \\
\hline Partner Retired & $\begin{array}{l}-0.01 \\
(0.04)\end{array}$ & $\begin{array}{c}0.00 \\
(0.06) \\
\end{array}$ & $\begin{array}{l}-0.06 \\
(0.06) \\
\end{array}$ & $\begin{array}{c}-0.36 \\
(0.71) \\
\end{array}$ & $\begin{array}{c}9.42^{* *} \\
(4.46)\end{array}$ & $\begin{array}{c}2.49^{* * *} \\
(0.28)\end{array}$ & $\begin{array}{c}2.29^{* * *} \\
(0.62)\end{array}$ & $\begin{array}{c}0.14^{* * *} \\
(0.03)\end{array}$ & $\begin{array}{c}0.10^{* * * *} \\
(0.03)\end{array}$ & $\begin{array}{c}-0.20^{*} \\
(0.11) \\
\end{array}$ \\
\hline Country \& Year FE & Yes & Yes & Yes & Yes & Yes & Yes & Yes & Yes & Yes & Yes \\
\hline Flexible Age Functions & Yes & Yes & Yes & Yes & Yes & Yes & Yes & Yes & Yes & Yes \\
\hline Number of Observations & 13762 & 13762 & 10487 & 8690 & 1667 & 13761 & 9206 & 9206 & 4747 & 12782 \\
\hline \multicolumn{11}{|c|}{ Subsample: Non-Retirees } \\
\hline Outcome Variable & Moderate PA & Vigorous PA & Smoking & $\begin{array}{l}\text { Cigarettes } \\
\text { (incl. 0's) }\end{array}$ & $\begin{array}{l}\text { Cigarettes } \\
\text { (excl. 0's) }\end{array}$ & Alcohol Freq. & Drinks & Binge Drinking & Drinking Problem & Health \\
\hline Partner Retired & $\begin{array}{c}-0.08^{* *} \\
(0.04)\end{array}$ & $\begin{array}{c}0.07 \\
(0.05)\end{array}$ & $\begin{array}{c}0.13^{* *} \\
(0.06)\end{array}$ & $\begin{array}{c}0.10 \\
(0.72)\end{array}$ & $\begin{array}{c}3.55 \\
(3.35)\end{array}$ & $\begin{array}{c}1.64^{* * *} \\
(0.24)\end{array}$ & $\begin{array}{l}1.50^{*} \\
(0.86)\end{array}$ & $\begin{array}{c}0.17^{* * *} \\
(0.04)\end{array}$ & $\begin{array}{c}0.11^{* * * *} \\
(0.04)\end{array}$ & $\begin{array}{c}-0.23^{* *} \\
(0.11)\end{array}$ \\
\hline Country \& Year FE & Yes & Yes & Yes & Yes & Yes & Yes & Yes & Yes & Yes & Yes \\
\hline Flexible Age Functions & Yes & Yes & Yes & Yes & Yes & Yes & Yes & Yes & Yes & Yes \\
\hline Number of Observations & 10277 & 10277 & 7117 & 5646 & 1118 & 10267 & 6086 & 6086 & 3086 & 9512 \\
\hline
\end{tabular}

Notes: Fuzzy RD estimates for the partner's retirement effects in the subsamples of retirees and non-retirees. The instruments for partner's retirement are an indicator for the spouse crossing the official

country-specific official retirement age and an interaction of the indicator with centered partner's age. Standard errors clustered at the individual level in parentheses: $* * * p<0.01 * * p<0.05 * p<0.1$. 
Figure 1: First-stage effects:

discontinuities in the retirement rates
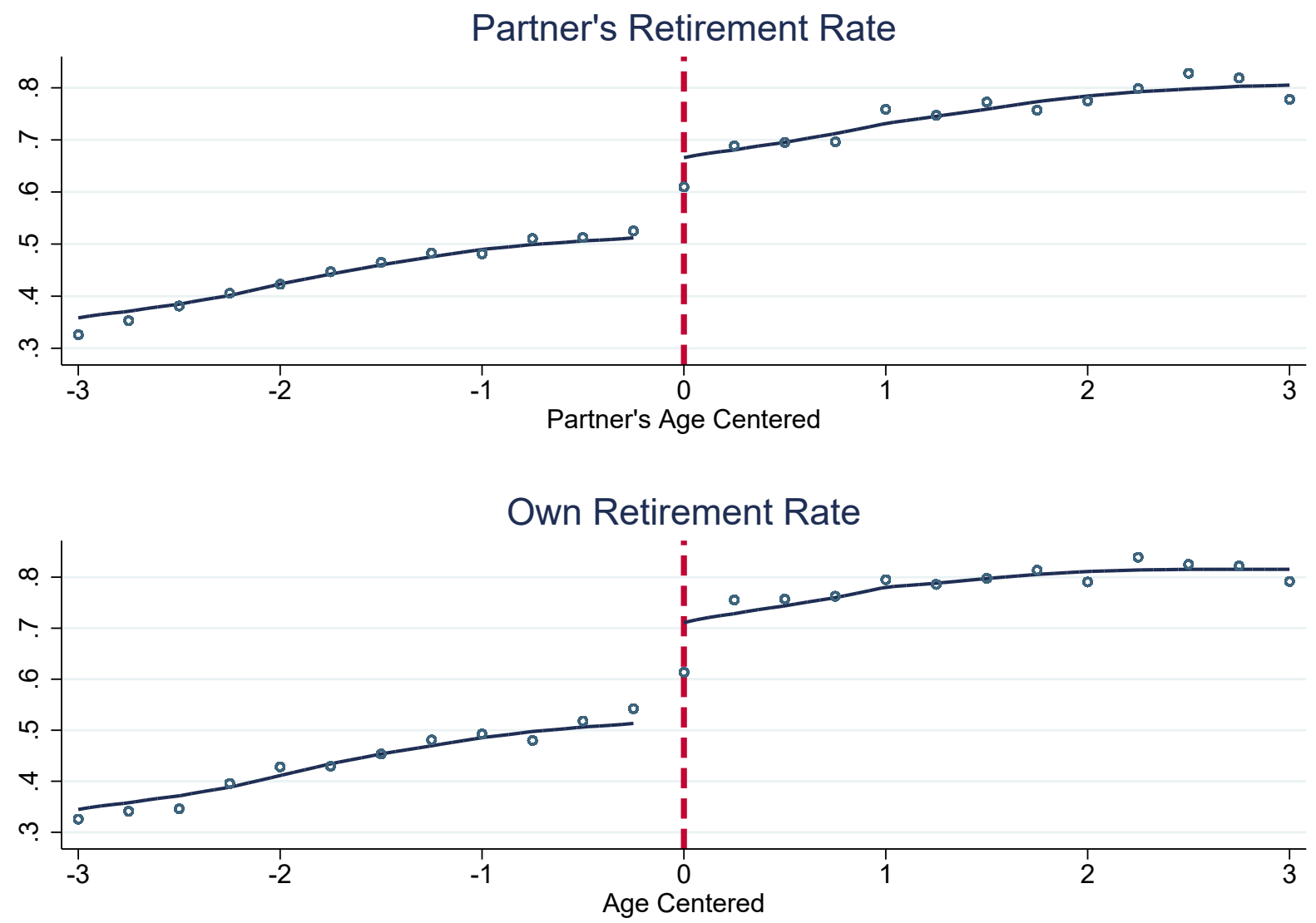

Notes: The figure shows the discontinuities in the retirement rates at the country-specific retirement ages. Partner's (own) age is centered at the retirement cutoffs. The scatters are overlaid with local polynomial smooths (dark blue lines). 


\section{Appendix A1: RD validity checks I}

Figure 2: Density of forcing variable

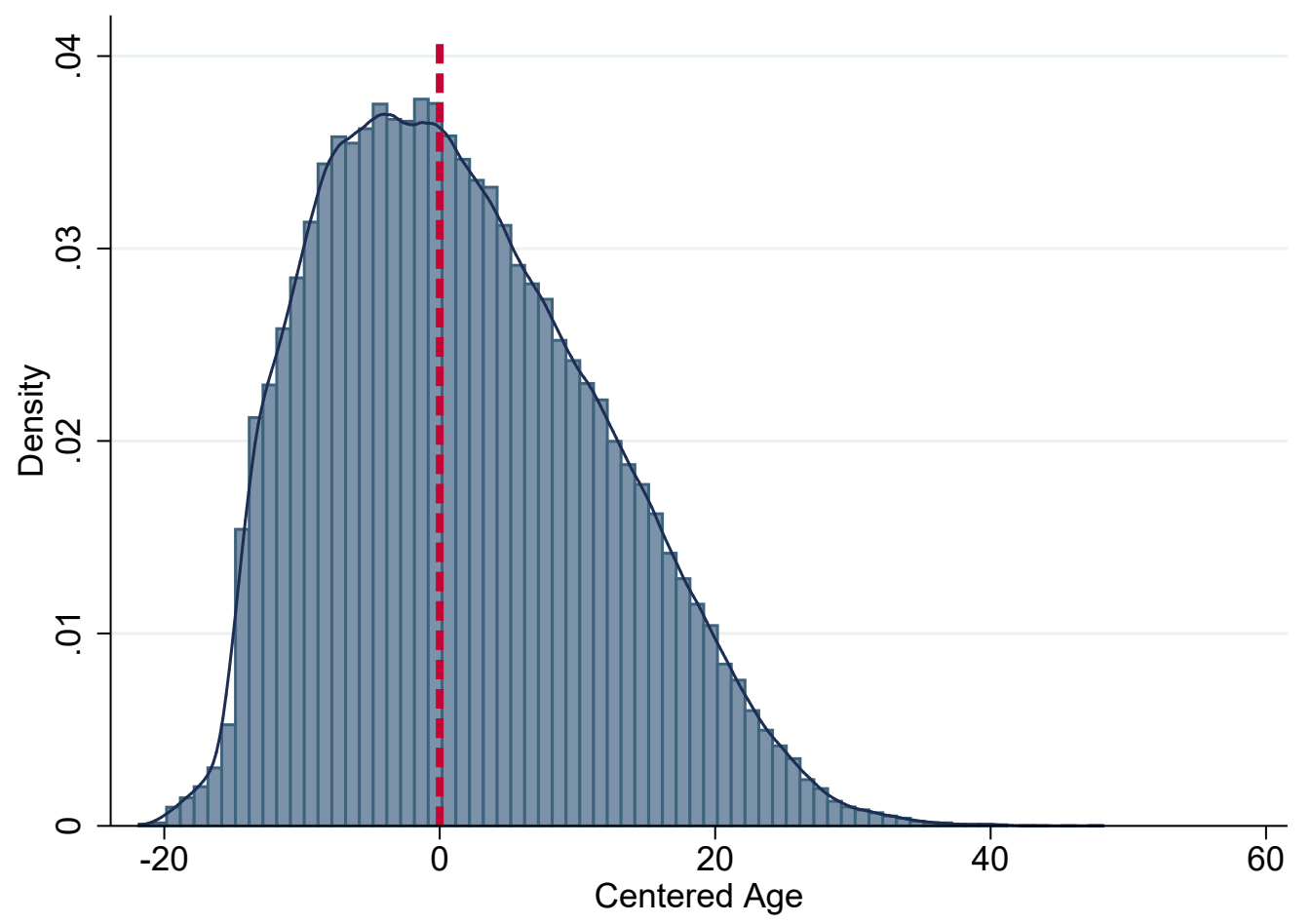

Notes: The figure shows the distribution of age around the official retirement cutoff. Age is centered at the country-specific retirement age. The dashed line indicates the retirement cutoff. 


\section{Appendix A2: RD validity checks II}

Figure 3: Baseline covariates
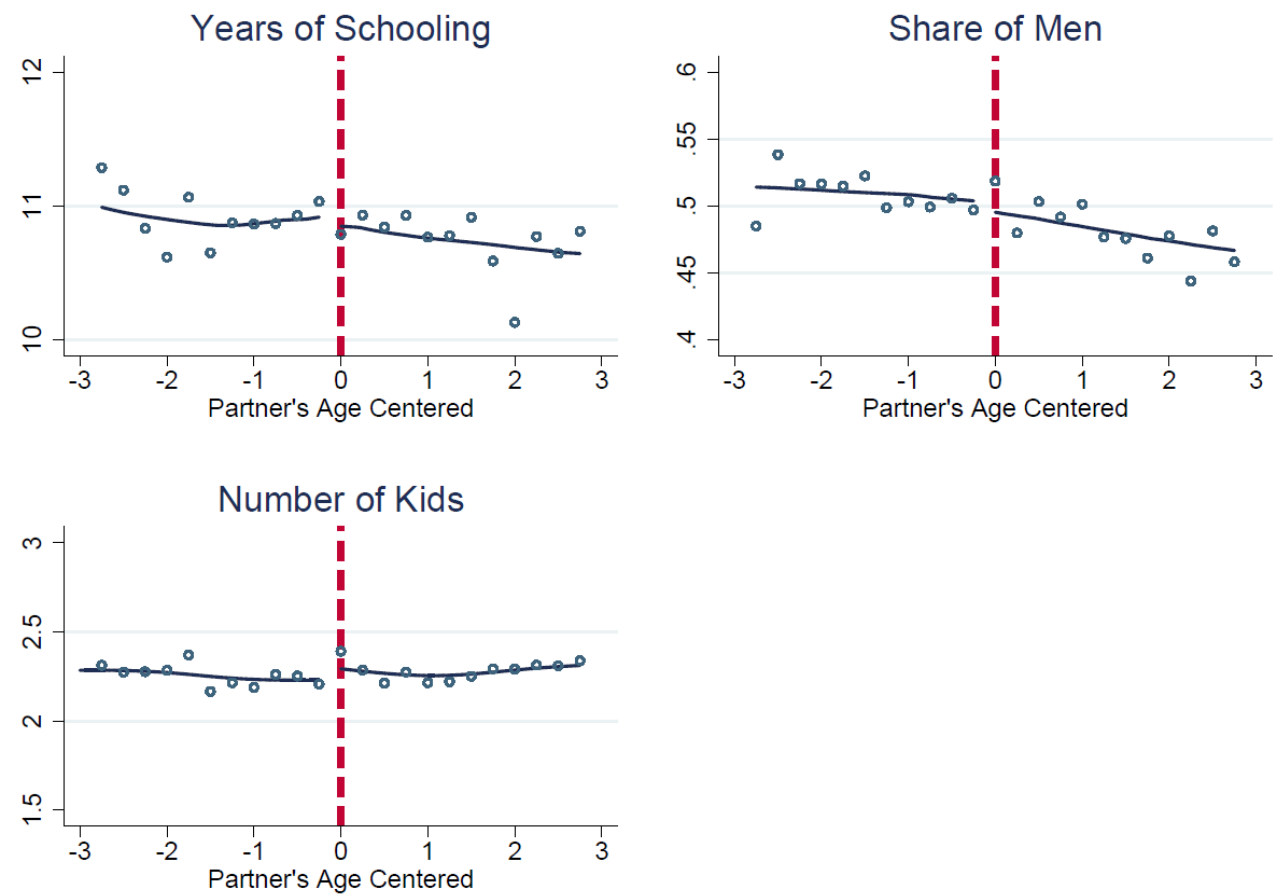

Notes: The figure shows the reduced-form effects for the predetermined covariates education, gender and number of kids around the retirement cutoff (dashed lines). The scatters are overlaid with local polynomial smooths (dark blue lines). Partner's age is centered at the country-specific retirement age. 


\section{Appendix A3: Reduced-form effects I}

Table 8: Reduced-form effects:

spousal- and own retirement

\begin{tabular}{|c|c|c|c|c|c|c|c|c|c|}
\hline \multicolumn{10}{|l|}{ Retirement Effects } \\
\hline Outcome Variable & Moderate PA & Vigorous PA & Smoking & Cigarettes & Alcohol Freq. & Drinks & Binge Drinking & Drinking Problem & Subjective Health \\
\hline Partner Retired & $\begin{array}{l}-0.051^{*} \\
(0.027)\end{array}$ & $\begin{array}{l}-0.005 \\
(0.038)\end{array}$ & $\begin{array}{c}0.013 \\
(0.039)\end{array}$ & $\begin{array}{l}-0.258 \\
(0.510)\end{array}$ & $\begin{array}{c}1.820^{* * *} \\
(0.175)\end{array}$ & $\begin{array}{c}1.613^{* * *} \\
(0.544)\end{array}$ & $\begin{array}{c}0.099^{* * *} \\
(0.026)\end{array}$ & $\begin{array}{c}0.104^{* * *} \\
(0.022)\end{array}$ & $\begin{array}{c}-0.364^{* * *} \\
(0.078)\end{array}$ \\
\hline Reduced-Form Effect & $\begin{array}{l}-0.006 \\
(0.006)\end{array}$ & $\begin{array}{c}0.005 \\
(0.009)\end{array}$ & $\begin{array}{c}0.003 \\
(0.009)\end{array}$ & $\begin{array}{l}-0.060 \\
(0.116)\end{array}$ & $\begin{array}{c}0.552^{* * *} \\
(0.037)\end{array}$ & $\begin{array}{c}0.490^{* * *} \\
(0.138)\end{array}$ & $\begin{array}{c}0.031^{* * *} \\
(0.006)\end{array}$ & $\begin{array}{c}0.030^{* * *} \\
(0.006)\end{array}$ & $\begin{array}{c}-0.066^{* * *} \\
(0.018)\end{array}$ \\
\hline First-Stage Effect & $\begin{array}{c}0.242^{* * *} \\
(0.008)\end{array}$ & $\begin{array}{c}0.242^{* * *} \\
(0.008)\end{array}$ & $\begin{array}{c}0.246^{* * *} \\
(0.009)\end{array}$ & $\begin{array}{c}0.241^{* * *} \\
(0.008)\end{array}$ & $\begin{array}{c}0.241^{* * *} \\
(0.011)\end{array}$ & $\begin{array}{c}0.266^{* * *} \\
(0.010)\end{array}$ & $\begin{array}{c}0.266^{\text {*** }} \\
(0.010)\end{array}$ & $\begin{array}{c}0.283^{* * *} \\
(0.014)\end{array}$ & $\begin{array}{c}0.247^{* * *} \\
(0.008)\end{array}$ \\
\hline Retired & $\begin{array}{c}0.058^{* * *} \\
(0.019)\end{array}$ & $\begin{array}{l}0.055^{*} \\
(0.028)\end{array}$ & $\begin{array}{l}-0.002 \\
(0.029)\end{array}$ & $\begin{array}{c}0.010 \\
(0.334)\end{array}$ & $\begin{array}{c}1.044^{* * *} \\
(0.133)\end{array}$ & $\begin{array}{c}0.649 \\
(0.407)\end{array}$ & $\begin{array}{l}0.050^{* *} \\
(0.020)\end{array}$ & $\begin{array}{c}0.002 \\
(0.018)\end{array}$ & $\begin{array}{c}0.232^{* * *} \\
(0.059)\end{array}$ \\
\hline Reduced-Form Effect & $\begin{array}{c}0.021^{* * *} \\
(0.007)\end{array}$ & $\begin{array}{l}0.019^{*} \\
(0.010)\end{array}$ & $\begin{array}{l}-0.001 \\
(0.010)\end{array}$ & $\begin{array}{c}0.009 \\
(0.121)\end{array}$ & $\begin{array}{c}0.318^{* * *} \\
(0.045)\end{array}$ & $\begin{array}{c}0.207 \\
(0.139)\end{array}$ & $\begin{array}{c}0.016^{* *} \\
(0.007)\end{array}$ & $\begin{array}{l}-0.001 \\
(0.006)\end{array}$ & $\begin{array}{c}0.089^{* * *} \\
(0.021)\end{array}$ \\
\hline First-Stage Effect & $\begin{array}{c}0.348^{* * *} \\
(0.009)\end{array}$ & $\begin{array}{c}0.348^{* * *} \\
(0.009)\end{array}$ & $\begin{array}{c}0.350^{* * *} \\
(0.010)\end{array}$ & $\begin{array}{c}0.350^{* * *} \\
(0.011)\end{array}$ & $\begin{array}{c}0.348^{* * *} \\
(0.009)\end{array}$ & $\begin{array}{c}0.343^{* * *} \\
(0.011)\end{array}$ & $\begin{array}{c}0.343^{\text {*** }} \\
(0.011)\end{array}$ & $\begin{array}{c}0.343^{* * *} \\
(0.015)\end{array}$ & $\begin{array}{c}0.348^{* * *} \\
(0.009)\end{array}$ \\
\hline Number of Observations & 24150 & 24150 & 17619 & 14346 & 24054 & 15304 & 15304 & 7844 & 22325 \\
\hline
\end{tabular}

Notes: Fuzzy RD estimates, reduced-form and first-stage effects of partner's and own retirement retirement on physical activity, smoking and alcohol consumption and subjective health. The RD estimates correspond to the estimates of specification (1) in tables 4 and 5. The reduced-form effects are generated by the Stata module ivreg2. The instruments for partner's and own retirement are indicators for

crossing the official country-specific official retirement age. Standard errors clustered at the individual level in parentheses: $* * * p<0.01 \quad * * p<0.05 * p<0.1$. 


\section{Appendix A4: Reduced-form effects II}

Figure 4: Spousal retirement:

reduced-form effects
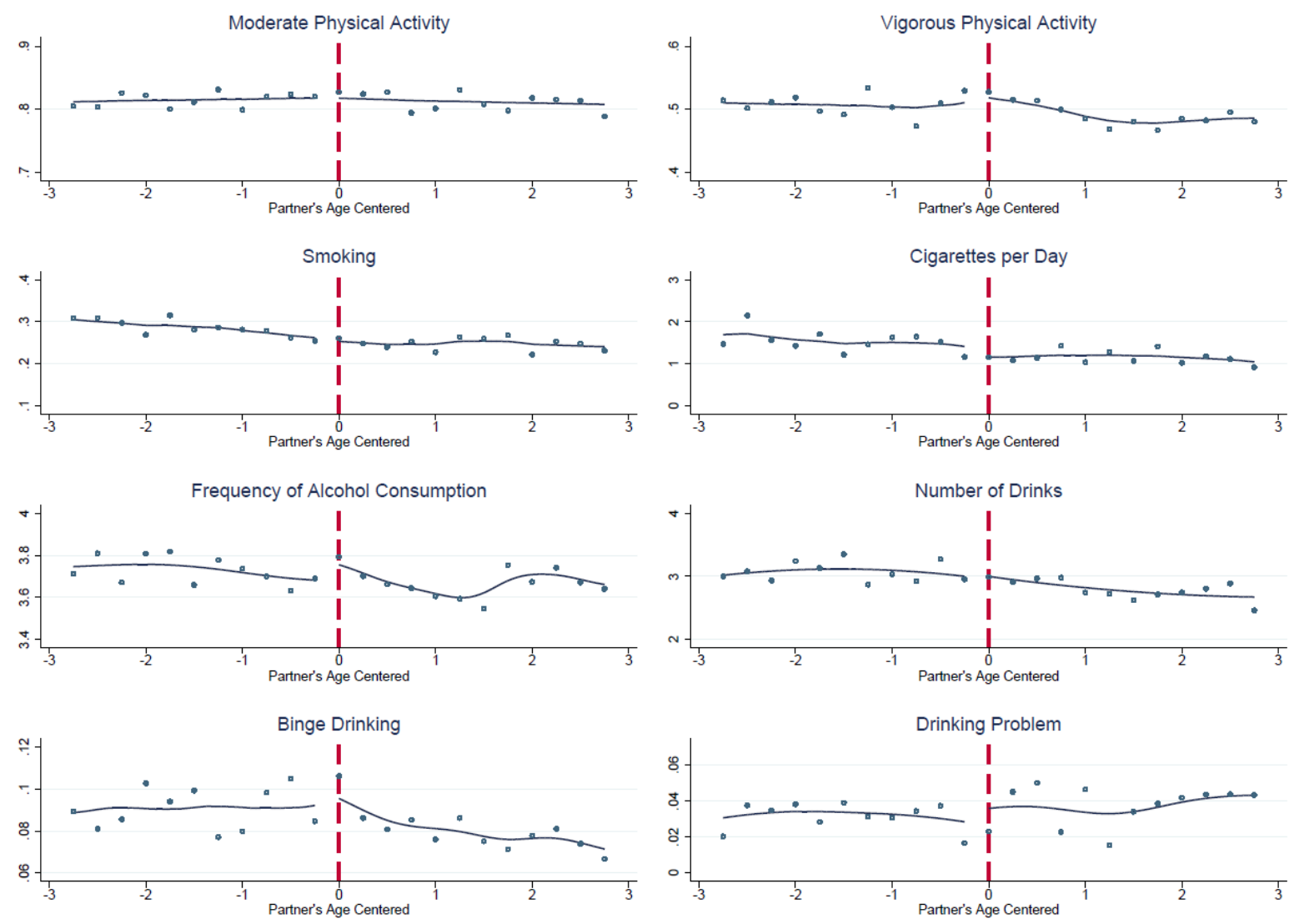

Notes: The figure shows the reduced-form effects for physical activity, tobacco and alcohol consumption. The scatters are overlaid with local polynomial smooth plots (dark blue lines). 
Figure 5: Own retirement:

reduced-form effects
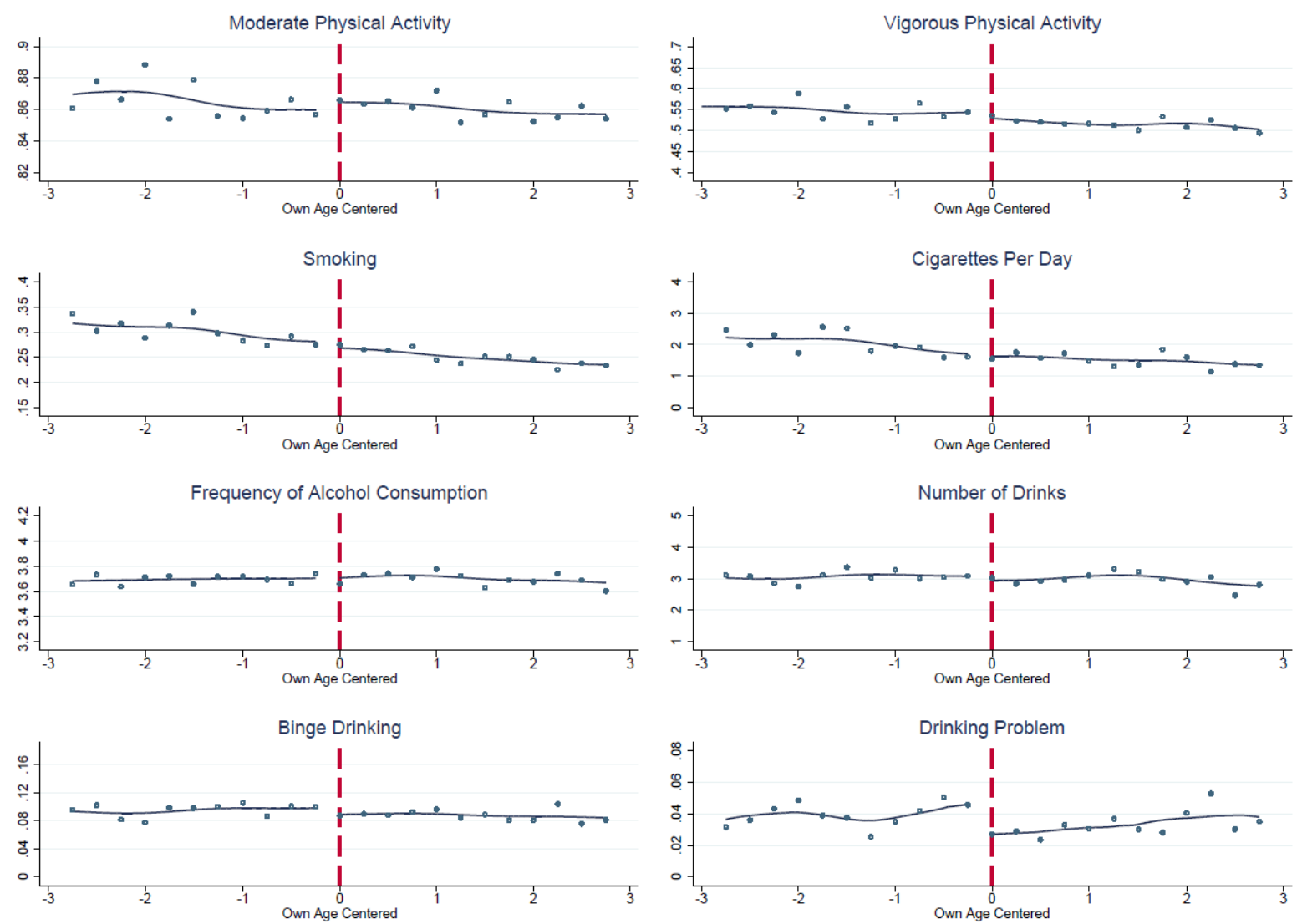

Notes: The figure shows the reduced-form effects for physical activity, tobacco and alcohol consumption. The scatters are overlaid with local polynomial smooth plots (dark blue lines). 
Figure 6: Reduced-form effects for subjective health
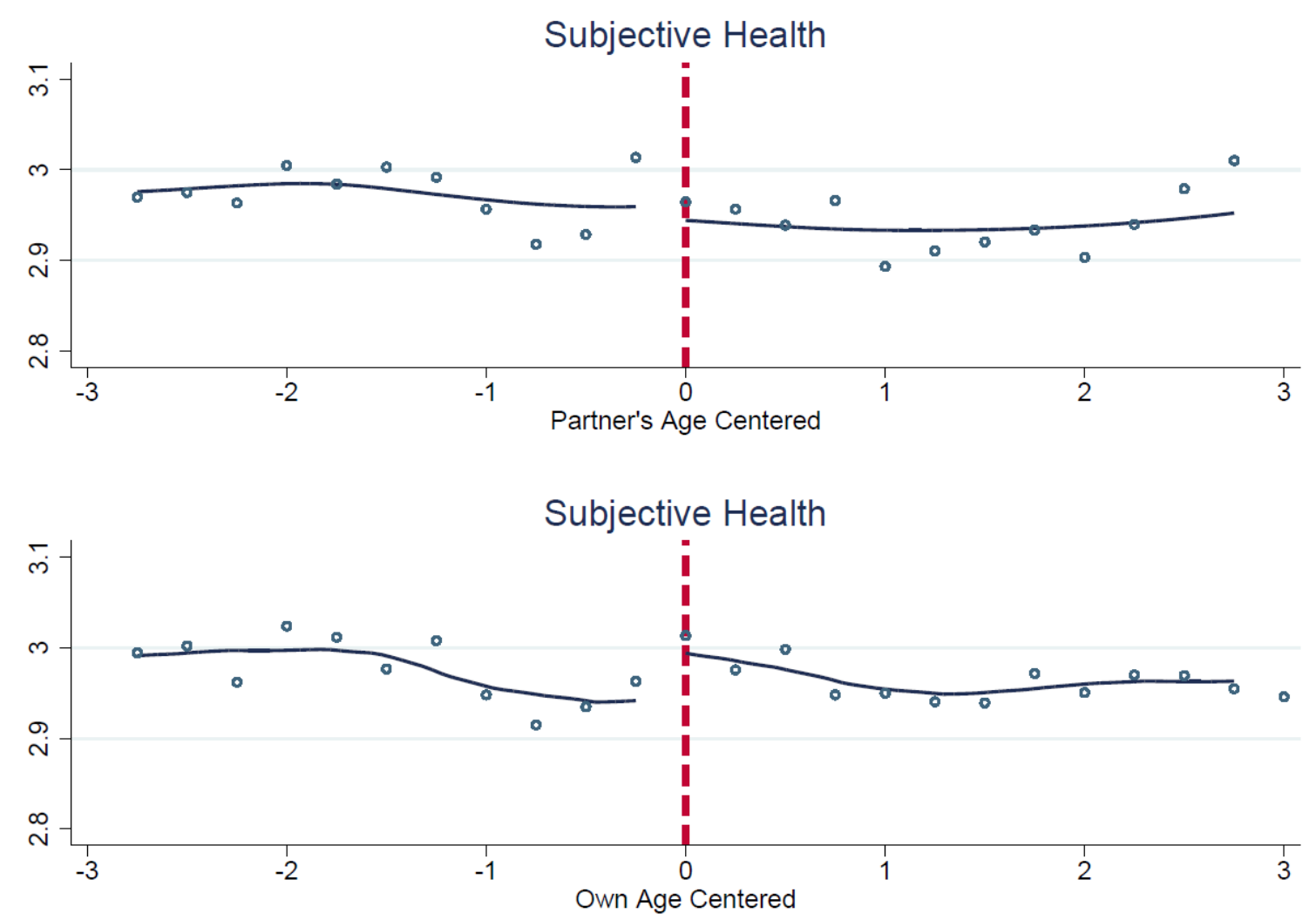

Notes: The figure shows the reduced-form effect for subjective health for both spousal (top graph) and own retirement (bottom graph). The scatters are overlaid with local polynomial smooth plots (dark blue lines). 


\section{Appendix A5: Retirement effects - Robustness I}

Table 9: Robustness checks:

varying window width

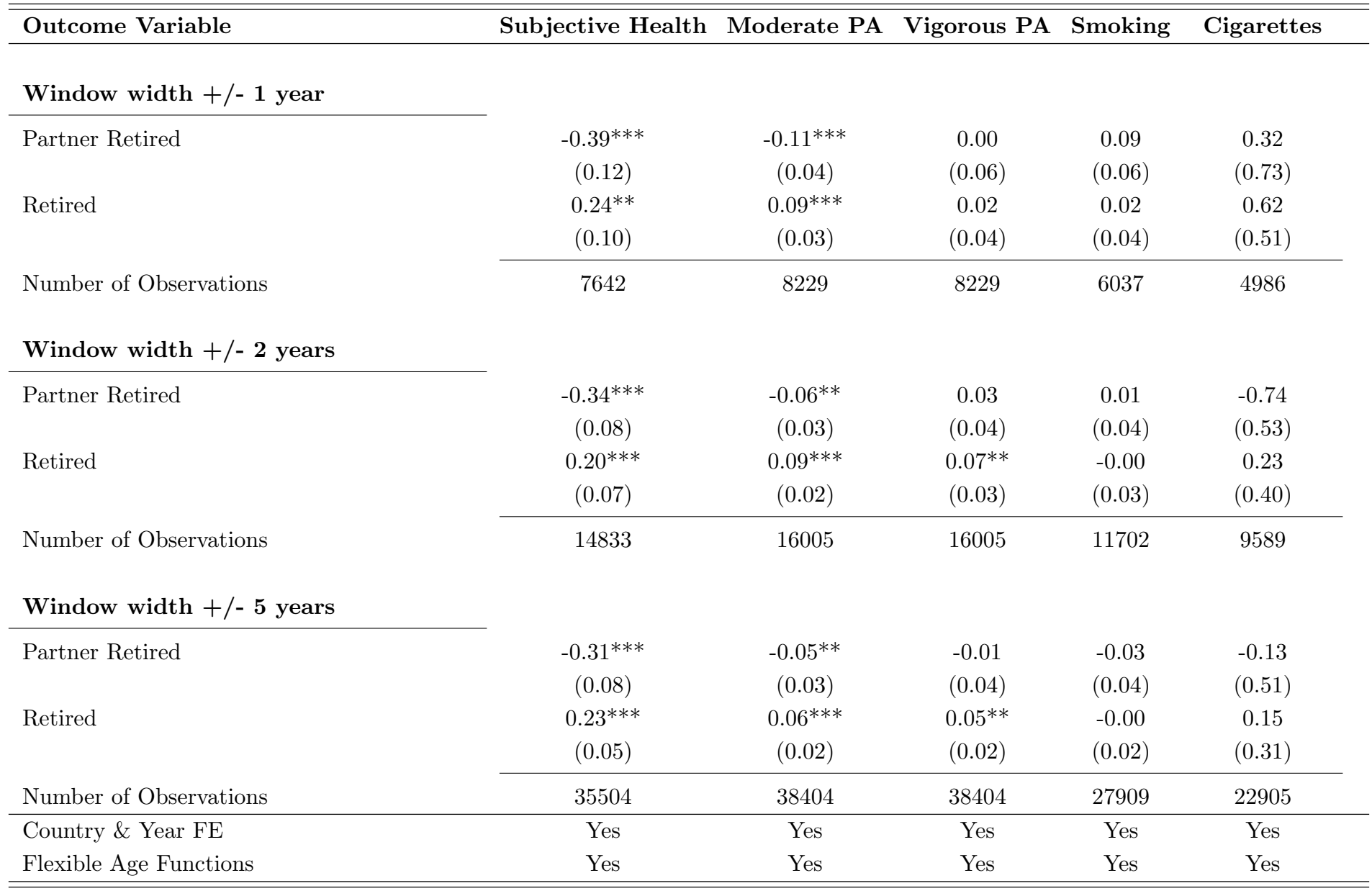

Notes: Fuzzy RD estimates for different bandwidths using each of the outcome variables as dependent variable. The instruments for partner's and own retirement are an indicator for crossing the official country-specific retirement age and interactions of the indicator with age. Standard errors clustered at the individual level in parentheses: ${ }^{* *} p<0.01{ }^{* *} p<0.05 * p<0.1$. 
Table 10: Robustness checks:

varying window width

\begin{tabular}{|c|c|c|c|c|}
\hline Outcome Variable & Alc. Freq. & Drinks & Binge Drinking & Drinking Problem \\
\hline \multicolumn{5}{|c|}{ Window width +/- 1 year } \\
\hline \multirow[t]{2}{*}{ Partner Retired } & $1.62^{* * *}$ & $2.18^{* *}$ & $0.13^{* * *}$ & $0.11^{* * *}$ \\
\hline & $(0.26)$ & $(0.89)$ & $(0.04)$ & $(0.03)$ \\
\hline \multirow{2}{*}{ Retired } & $1.05^{* * *}$ & 0.11 & 0.01 & -0.00 \\
\hline & $(0.20)$ & $(0.66)$ & $(0.04)$ & $(0.03)$ \\
\hline Number of Observations & 8224 & 5218 & 5218 & 2734 \\
\hline \multicolumn{5}{|c|}{ Window width $+/-2$ years } \\
\hline \multirow[t]{2}{*}{ Partner Retired } & $1.69^{* * *}$ & $1.71^{* * *}$ & $0.11^{* * *}$ & $0.11^{* * *}$ \\
\hline & $(0.18)$ & $(0.58)$ & $(0.03)$ & $(0.03)$ \\
\hline \multirow[t]{2}{*}{ Retired } & $1.15^{* * *}$ & 0.57 & $0.05^{* *}$ & 0.00 \\
\hline & $(0.15)$ & $(0.41)$ & $(0.02)$ & $(0.02)$ \\
\hline Number of Observations & 15996 & 10148 & 10148 & 5324 \\
\hline \multicolumn{5}{|c|}{ Window width $+/-5$ years } \\
\hline \multirow[t]{2}{*}{ Partner Retired } & $2.01^{* * *}$ & $0.91^{* *}$ & $0.09 * * *$ & $0.09 * * *$ \\
\hline & $(0.17)$ & $(0.46)$ & $(0.02)$ & $(0.02)$ \\
\hline \multirow[t]{2}{*}{ Retired } & $0.63^{* * *}$ & 0.44 & 0.01 & -0.01 \\
\hline & $(0.11)$ & $(0.30)$ & $(0.02)$ & $(0.01)$ \\
\hline Number of Observations & 38386 & 24040 & 24040 & 12424 \\
\hline Country \& Year FE & Yes & Yes & Yes & Yes \\
\hline Flexible Age Functions & Yes & Yes & Yes & Yes \\
\hline
\end{tabular}

Notes: Fuzzy RD estimates for different bandwidths using each of the alcohol consumption related outcome variables as dependent variable. The instruments for partner's and own retirement are indicators for crossing the official country-specific retirement age and interactions of the indicators with polynomials of centered age. Standard errors clustered at the individual level in parentheses: $* * * p<0.01 \quad * *$ $p<0.05 * p<0.1$. 


\section{Appendix A6: Retirement effects - Robustness II}

Table 11: Retirement effects:

allowing for non-linearities

\begin{tabular}{|c|c|c|c|c|c|c|c|c|c|}
\hline \multicolumn{10}{|l|}{ Retirement Effects } \\
\hline Outcome Variable & Moderate PA & Vigorous PA & Smoking & Cigarettes & Alcohol Freq. & Drinks & Binge Drinking & Drinking Problem & Subjective Health \\
\hline \multirow[t]{2}{*}{ Partner Retired } & -0.05 & 0.02 & -0.00 & -0.00 & $1.99^{* * *}$ & $1.51^{* *}$ & $0.10^{* * *}$ & $0.11^{* * *}$ & $-0.43^{* * *}$ \\
\hline & $(0.03)$ & $(0.04)$ & $(0.04)$ & $(0.04)$ & $(0.22)$ & $(0.59)$ & $(0.03)$ & $(0.02)$ & $(0.09)$ \\
\hline \multirow[t]{2}{*}{ Retired } & 0.06 & -0.00 & 0.04 & 0.04 & -0.22 & 0.09 & 0.03 & -0.05 & $0.46^{* * *}$ \\
\hline & $(0.04)$ & $(0.06)$ & $(0.06)$ & $(0.06)$ & $(0.34)$ & $(0.89)$ & $(0.04)$ & $(0.04)$ & $(0.14)$ \\
\hline Country \& Year FE & Yes & Yes & Yes & Yes & Yes & Yes & Yes & Yes & Yes \\
\hline Linear Age Functions & Yes & Yes & Yes & Yes & Yes & Yes & Yes & Yes & Yes \\
\hline Quadratic Age Function & Yes & Yes & Yes & Yes & Yes & Yes & Yes & Yes & Yes \\
\hline Number of Observations & 23598 & 23598 & 17229 & 17229 & 23587 & 14927 & 14927 & 7744 & 21854 \\
\hline
\end{tabular}

Notes: Fuzzy RD estimates of the effects of partner's and own retirement retirement on physical activity, smoking and alcohol consumption and subjective health. The endogenous variables are the indicators for retirement and interactions of these indicators with centered age and age squared. The instruments for partner's and own retirement are indicators for crossing the official country-specific official retirement age and interactions of the indicator with polynomials of centered age for both own age and partner's age. Standard errors clustered at the individual level in parentheses:

*** $p<0.01 * * p<0.05 * p<0.1$ 


\section{Appendix A7: Retirement effects - Robustness III}

Table 12: Retirement effects:

further baseline covariates

\begin{tabular}{|c|c|c|c|c|c|c|c|c|c|}
\hline \multicolumn{10}{|l|}{ Retirement Effects } \\
\hline Outcome Variable & Moderate PA & Vigorous PA & Smoking & Cigarettes & Alcohol Freq. & Drinks & Binge Drinking & Drinking Problem & Subjective Health \\
\hline \multirow[t]{2}{*}{ Partner Retired } & -0.02 & -0.00 & -0.04 & 0.89 & $1.35^{* * *}$ & $2.11^{* * *}$ & $0.09^{* *}$ & $0.10^{* * *}$ & $-0.25^{* *}$ \\
\hline & $(0.04)$ & $(0.05)$ & $(0.07)$ & $(0.98)$ & $(0.23)$ & $(0.79)$ & $(0.04)$ & $(0.03)$ & $(0.11)$ \\
\hline \multirow[t]{2}{*}{ Retired } & $0.05^{*}$ & 0.07 & 0.01 & 0.37 & $1.15^{* * *}$ & 0.60 & $0.05^{* *}$ & 0.00 & $0.33^{* * *}$ \\
\hline & $(0.03)$ & $(0.04)$ & $(0.05)$ & $(0.81)$ & $(0.17)$ & $(0.50)$ & $(0.03)$ & $(0.02)$ & $(0.09)$ \\
\hline Country \& Year FE & Yes & Yes & Yes & Yes & Yes & Yes & Yes & Yes & Yes \\
\hline Flexible Age Function & Yes & Yes & Yes & Yes & Yes & Yes & Yes & Yes & Yes \\
\hline Education & Yes & Yes & Yes & Yes & Yes & Yes & Yes & Yes & Yes \\
\hline Number of Observations & 11525 & 11525 & 6883 & 5504 & 11519 & 8354 & 8354 & 5186 & 11517 \\
\hline
\end{tabular}

Notes: Fuzzy RD estimates of the effects of partner's and own retirement retirement on physical activity, smoking and alcohol consumption and subjective health. The instruments for partner's and own retirement are indicators for crossing the official country-specific official retirement age and an interaction of the indicator with centered partner's age. Standard errors clustered at the individual level in parentheses: ${ }^{* * *} p<0.01 * * p<0.05 * p<0.1$. 


\section{References}

Alexander, F., \& Duff, R. W. (1988). Social interaction and alcohol use in retirement communities. The Gerontologist, 28(5): 632-636.

Angrist, J. D., \& Pischke, J. S. (2008). Mostly Harmless Econometrics: An empiricist's companion. Princeton university press.

Angrist, J. D. \& Imbens, G. W. (1995). Two-stage least squares estimation of average causal effects in models with variable treatment intensity. Journal of the American statistical Association, 90(430): 431-442.

Bacharach, S. B., Bamberger, P. A., Sonnenstuhl, W. J., \& Vashdi, D. (2004). Retirement, risky alcohol consumption and drinking problems among blue-collar workers. Journal of Studies on Alcohol, 65(4): 537-545.

Bamberger, P. A. (2015). Winding down and boozing up: The complex link between retirement and alcohol misuse. Work, Aging and Retirement, 1(1): 92-111.

Battistin, E., Brugiavini, A., Rettore, E., \& Weber, G. (2009). The retirement consumption puzzle: evidence from a regression discontinuity approach. American Economic Review, 99(5): 2209-26.

Bamia, C., Trichopoulou, A., \& Trichopoulos, D. (2007). Age at Retirement and Mortality in a General Population Sample. American Journal of Epidemiology, 167(5): 561-569.

Banerjee, A. V. (1992). A simple model of herd behavior. The Quarterly Journal of Economics, 107(3): 797-817.

Banks, J., Blundell, R., \& Casanova, M. (2010). The dynamics of retirement behavior in couples: Evidence from the UK and the US. Mimeo, UCLA. Available from http: //www.econ.ucla.edu/casanova/Files/Main_ELSA_HRS.pdf [Last accessed 14 August 2016].

Behncke, S. (2012). Does retirement trigger ill health? Health Economics, 21(3): 282-300.

Bernheim, B. D. (1994). A theory of conformity. Journal of Political Economy, 102(5): 841-877.

Bertoni, M. \& Brunello, G. (2017). Pappa Ante Portas: The effect of the husband's retirement on the wife's mental health in Japan. Social Science \& Medicine, 175, 135-142.

Bikhchandani, S., Hirshleifer, D., \& Welch, I. (1992). A theory of fads, fashion, custom, and cultural change as informational cascades. Journal of Political Economy, 105(5): 992-1026. 
Bonsang, E., Adam, S., \& Perelman, S. (2012). Does retirement affect cognitive functioning?. Journal of Health Economics, 31(3), 490-501.

Blau, D. M. (2008). Retirement and consumption in a life cycle model. Journal of Labor Economics, 26(1), 35-71.

Blake, H. \& Garrouste, C. (2013). Killing me softly: work and mortality among French seniors. Health, Econometrics and Data Group (HEDG) Working Papers, HEDG, c/o Department of Economics, University of York. Available from https://www.york.ac.uk/ media/economics/documents/hedg/workingpapers/13_25.pdf [Last accessed 14 August $2016]$.

Bloemen, H., Hochguertel, S., \& Zweerink, J. (2013). The Causal Effect of Retirement on Mortality: Evidence from Targeted Incentives to Retire Early. Tinbergen Institute Discussion Paper 13-119/V. Available at SSRN: http://ssrn.com/abstract=2312333 [Last accessed 14 August 2016].

Börsch-Supan, A. (2016a). Survey of Health, Ageing and Retirement in Europe (SHARE) Wave 1. Release version: 5.0.0. SHARE-ERIC. Data set. DOI: 10.6103/SHARE.w1.500.

Börsch-Supan, A. (2016b). Survey of Health, Ageing and Retirement in Europe (SHARE) Wave 2. Release version: 5.0.0. SHARE-ERIC. Data set. DOI: 10.6103/SHARE.w2.500.

Börsch-Supan, A. (2016c). Survey of Health, Ageing and Retirement in Europe (SHARE) Wave 4. Release version: 5.0.0. SHARE-ERIC. Data set. DOI: 10.6103/SHARE.w4.500.

Börsch-Supan, A. (2016d). Survey of Health, Ageing and Retirement in Europe (SHARE) Wave 5. Release version: 5.0.0. SHARE-ERIC. Data set. DOI: 10.6103/SHARE.w5.500.

Cawley, J. \& Ruhm, J. (2011). Chapter Three - The Economics of Risky Health behaviors, Handbook of Health Economics, 2, 95-199.

Celidoni, M., Bianca, C., \& Weber, G. (2013). Early retirement and cognitive decline. A longitudinal analysis using SHARE data. Marco Fanno Working Paper No. 174. Available from http://citeseerx.ist.psu.edu/viewdoc/download?doi=10.1.1.684.4534\&rep= rep1\&type=pdf [Last accessed 14 August 2016]

Charles, K. (2002). Is retirement depressing? Labor force inactivity and psychological well-being in later life. Research in Labor Economics, 23, 269-299.

Chung, S., Domino, M., Stearns, S.C., \& Popkin, B.M. (2009). Retirement and physical activity: analyses by occupation and wealth. Am J Prev Med, 36(5), 422-428.

Coe, N.B. \& Lindeboom, M. (2008). Does Retirement Kill You? Evidence from Early Retirement Windows, CentER Discussion Paper Series No. 2008-93. Available at SSRN: http://ssrn.com/abstract=1295315 or http://dx.doi.org/10.2139/ssrn.1295315 [Last accessed 14 August 2016].

Coe, N.B. \& Zamarro, G. (2011). Retirement effects on health in Europe, Journal of Health Economics, 30(1): 77-86. 
Coile, C. (2004). Retirement incentives and couples' retirement decisions. The B.E. Journal of Economic Analysis \& Policy, De Gruyter, 4(1): 1-30.

Courtney, K. E., \& Polich, J. (2009). Binge drinking in young adults: Data, definitions, and determinants. Psychological bulletin, 135(1), 142.

Cribb, J., Emmerson, C., \& Tetlow, G. (2014). How does increasing the early retirement age for women affect the labour supply of women and their husbands?. Netspar Discussion Paper No. 01/2014-003. Available at SSRN: http://ssrn.com/abstract=2411433 or http://dx.doi.org/10.2139/ssrn.2411433. [Last accessed 14 August 2016].

Dave, D., Rashad, I., \& Spasojevic, J. (2008). The Effects of Retirement on Physical and Mental Health Outcomes. Southern Economic Journal, 75(2), 497-523.

Duflo, E., \& Saez, E. (2002). Participation and investment decisions in a retirement plan: The influence of colleagues' choices. Journal of Public Economics, 85(1), 121-148.

Duflo, E., \& Saez, E. (2003). The Role of Information and Social Interactions in Retirement Plan Decisions: Evidence from a Randomized Experiment. The Quarterly Journal of Economics, 118(3), 815-842.

Eibich, P. (2015). Understanding the effect of retirement on health: Mechanisms and Heterogeneity. Journal of Health Economics, 43, 1-12.

Ekerdt, D. J., De Labry, L. O., Glynn, R. J., \& Davis, R. W. (1989). Change in drinking behaviors with retirement: Findings from the normative aging study. Journal of Studies on Alcohol, 50, 347-353.

Figner, B., \& Weber, B.U. (2011. Who Takes Risks When and Why? : Determinants of Risk Taking. Current Directions in Psychological Science, 20(4): 211-216.

Fitzpatrick, M. D., \& Moore, T. (2016). The Mortality Effects of Retirement: Evidence from Social Security Eligibility at Age 62. Available at SSRN: https://ssrn.com/abstract=2830523.

Forman-Hoffman, V. L., Richardson, K. K., Yankey, J. W., Hillis, S. L., Wallace, R. B., \& Wolinsky, F. D. (2008). Retirement and weight changes among men and women in the health and retirement study. The Journals of Gerontology Series B: Psychological Sciences and Social Sciences, 63(3), S146-S153.

Gelman, A., \& Imbens, G. (2014) Why High-Order Polynomials Should Not Be Used in Regression Discontinuity Designs, No. w20405. National Bureau of Economic Research. Available from http://www.nber.org/papers/w20405 [Last accessed 14 August 2016].

Gibson, J. (2001). Literacy and Intra-household Externalities. World Development, 29(1), $155-166$.

Godard, M. (2016). Gaining weight through retirement? Results from the SHARE survey. Journal of Health Economics, 45, 27-46. 
Gorry, A., Gorry, D., \& Slavov, S. (2015). Does Retirement Improve Health and Life Satisfaction? (No. w21326). National Bureau of Economic Research.

Hahn, J., Todd, P., \& Van der Klaauw, W. (2001). Identification and estimation of treatment effects with a regression discontinuity design. Econometrica, 69(1), 201-209.

Hallberg, D. (2003). Synchronous Leisure, jointness and household labor supply. Labour Economics, 10(2): 185-203.

Hurd, M. D. (1990). The joint retirement decision of husbands and wives. In Issues in the Economics of Aging (pp. 231-258). University of Chicago Press, 1990.

Insler, M. (2014). The Health Consequences of Retirement, Journal of Human Resources, 49(1), 195-233.

Johnston, D. \& Lee, W.S. (2009). Retiring to the good life? The short-term effects of retirement on health, Economic Letters, 103(1): 8-11.

Kulik, L. (1999). Continuity and discontinuity in marital life after retirement: Life orientations, gender role ideology, intimacy and satisfaction. Families in Society, 80, 286-294.

Lee, D. S., \& Lemieux, T. (2010). Regression discontinuity designs in economics. Journal of Economic Literature, American Economic Association, 48(2): 281-355.

Lindelow, M. (2008). Health as a Family Matter: Do Intra-household Education Externalities Matter for Maternal and Child Health? The Journal of Development Studies, 44(4), $562-585$.

Manski, C. F. (1993). Identification of endogenous social effects: The reflection problem. The review of economic studies, 60(3), 531-542.

McCrary, J. (2008), Manipulation of the Running Variable in the Regression Discontinuity Design: A Density Test, Journal of Econometrics, 142 (2): 698-714.

Mazzonna, F., \& Peracchi, F. (2012). Ageing, cognitive abilities and retirement. European Economic Review, 56(4), 691-710.

Merrick, E. L. et al. (2008). Unhealthy drinking patterns and receipt of preventive medical services by older adults. Journal of General Internal Medicine, 23, 1741-1748.

Miller, G. \& Mobarak, A.M. (2013). Gender Differences in Preferences, Intra-Household Externalities, and Low Demand for Improved Cookstoves. NBER Working Paper No. 18964. Available from http://www.nber.org/papers/w18964 [Lastaccessed14August2016].

Moen, P., Kim, J.E. \& Hofmeister, H. (2001). Couples' work/retirement transitions, gender, and marital quality. Social Psychology Quarterly, 64(1), 55-71.

Moore, A. A. et al. (2005). Longitudinal patterns and predictors of alcohol consumption in the United States. American Journal of Public Health, 95, 458-465. 
Naimi, T. S., Brewer, R. D., Mokdad, A., Denny, C., Serdula, M. K., \& Marks, J. S. (2003). Binge drinking among US adults. Jama, 289(1), 70-75.

Neumann, K. (2008). Quit Your Job and Get Healthier? The Effect of Retirement on Health, Journal of Labor Research 29(2): 177-201.

OECD (2013). Pensions at a Glance 2013: OECD and G20 Indicators, OECD Publishing. http://dx.doi.org/10.1787/pension_glance-2013-en.

OECD (2014). Expected years in retirement, in Society at a Glance 2014: OECD Social Indicators, OECD Publishing, Paris.

Roux et al. (2008). Cost effectiveness of community-based physical activity interventions. Am J Prev Med,35(6):578-88.

Rust, J., \& Phelan, C. (1997). How social security and medicare affect retirement behavior in a world of incomplete markets. Econometrica: Journal of the Econometric Society, 65(4): 781-831.

Sacco et al., (2014). Drinking behavior among older adults at a continuing care retirement community: affective and motivational influences. Aging and Mental Health, 19(3): 279-289.

Saltman, R. B., Busse, R., \& Figueras, J. eds. 2004. Social Health Insurance Systems in Western Europe. Buckingham: Open University Press.

Smith, D.B., \& Moen, P. (2004). Retirement satisfaction for retirees and their spouses: Do gender and the retirement decision-making process matter? Journal of Family Issues, 25(2), 262-285.

Szinovacz, M.E. (1980). Female Retirement: Effects on Spousal Roles and Marital Adjustment. Journal of Family Issues. 1(3), 423-440.

Szinovacz, M.E. \& Davey, A. (2004). Honeymoon and Joint Lunches: Effects of Retirement and Spouse's Employment on Depressive Symptoms. Journal of Gerontology, 59B(5), 233-245.

Stancanelli, E., \& Soest, A. (2012). Retirement and Home Production: A Regression Discontinuity approach, American Economic Review, Papers and Proceedings, 102(3):600-605.

Stancanelli, E., \& Soest, A. (2016). Partners' leisure time truly together upon retirement. IZA Journal of Labor Policy 2016, 5:12.

Van Solinge, H. (2007). Health Change in Retirement A Longitudinal Study among Older Workers in the Netherlands. Research on Aging, 29(3), 225v256.

Vergari, C. (2004). Herd behaviour, Strategic Complementarities and Technology Adoption. CORE Discussion Paper No. 2004/63. Available from SSRN: http://ssrn.com/abstract=675584 [Last accessed 14 August 2016]. 
Wheaton, B. (1990). Life Transitions, Role Histories, and Mental Health. American Sociological Review, 55(2), 209-223.

Woolley, F.R. (1990). Economic models of family decision making, with applications to intergenerational justice. Unpublished Ph.D. dissertation, London School of Economics.

Zins, M., Guéguen, A., Kivimaki, M., Singh-Manoux, A., Leclerc, A., Vahtera, J. \& Goldberg, M. (2011). Effect of retirement on alcohol consumption: longitudinal evidence from the French Gazel cohort study. PLoS One, 6(10), e26531.

Zweimuller, J., Winter-Ebmer, R., \& Falkinger, J. (1996). Retirement of Spouses and Social Security Reform. European Economic Review, 40(2): 449-472. 